\title{
Intercomparison of fast response commercial gas analysers for nitrous oxide flux measurements under field conditions
}

\author{
Ü. Rannik ${ }^{1}$, S. Haapanala ${ }^{1}$, N. J. Shurpali ${ }^{2}$, I. Mammarella ${ }^{1}$, S. Lind ${ }^{2}$, N. Hyvönen ${ }^{2}$, O. Peltola ${ }^{1}$, M. Zahniser ${ }^{3}$, \\ P. J. Martikainen ${ }^{2}$, and T. Vesala ${ }^{1}$ \\ ${ }^{1}$ Department of Physics, P.O. Box 48, 00014 University of Helsinki, Helsinki, Finland \\ ${ }^{2}$ Department of Environmental Science, University of Eastern Finland, Kuopio, Finland \\ ${ }^{3}$ Center for Atmospheric and Environmental Chemistry, Aerodyne Research Inc., Billerica, MA, USA
}

Correspondence to: Ü. Rannik (ullar.rannik@ heuristica.ee)

Received: 19 May 2014 - Published in Biogeosciences Discuss.: 1 August 2014

Revised: 28 November 2014 - Accepted: 11 December 2014 - Published: 22 January 2015

\begin{abstract}
Four gas analysers capable of measuring nitrous oxide $\left(\mathrm{N}_{2} \mathrm{O}\right)$ concentration at a response time necessary for eddy covariance flux measurements were operated from spring until winter 2011 over a field cultivated with reed canary grass (RCG, Phalaris arundinacea, L.), a perennial bioenergy crop in eastern Finland. The instruments were TGA100A (Campbell Scientific Inc.), CW-TILDASCS (Aerodyne Research Inc.), $\mathrm{N}_{2} \mathrm{O} / \mathrm{CO}-23 \mathrm{~d}$ (Los Gatos Research Inc.) and QC-TILDAS-76-CS (Aerodyne Research Inc.). The period with high emissions, lasting for about 2 weeks after fertilization in late May, was characterized by an up to 2 orders of magnitude higher emission, whereas during the rest of the campaign the $\mathrm{N}_{2} \mathrm{O}$ fluxes were small, from 0.01 to $1 \mathrm{nmol} \mathrm{m}^{-2} \mathrm{~s}^{-1}$. Two instruments, CW-TILDAS-CS and $\mathrm{N}_{2} \mathrm{O} / \mathrm{CO}-23 \mathrm{~d}$, determined the $\mathrm{N}_{2} \mathrm{O}$ exchange with minor systematic difference throughout the campaign, when operated simultaneously. TGA100A produced the cumulatively highest $\mathrm{N}_{2} \mathrm{O}$ estimates (with $29 \%$ higher values during the period when all instruments were operational). QC-TILDAS-76-CS obtained 36\% lower fluxes than CWTILDAS-CS during the first period, including the emission episode, whereas the correspondence with other instruments during the rest of the campaign was good. The reasons for systematic differences were not identified, suggesting further need for detailed evaluation of instrument performance under field conditions with emphasis on stability, calibration and any other factors that can systematically affect the accuracy of flux measurements. The instrument CW-TILDAS-CS was characterized by the lowest noise level (with a standard deviation of around $0.12 \mathrm{ppb}$ at $10 \mathrm{~Hz}$ sampling rate) as compared
\end{abstract}

to $\mathrm{N}_{2} \mathrm{O} / \mathrm{CO}-23 \mathrm{~d}$ and QC-TILDAS-76-CS (around 0.50 ppb) and TGA100A (around $2 \mathrm{ppb}$ ). We identified that for all instruments except CW-TILDAS-CS the random error due to instrumental noise was an important source of uncertainty at the $30 \mathrm{~min}$ averaging level and the total stochastic error was frequently of the same magnitude as the fluxes when $\mathrm{N}_{2} \mathrm{O}$ exchange was small at the measurement site. Both instruments based on continuous-wave quantum cascade laser, CW-TILDAS-CS and $\mathrm{N}_{2} \mathrm{O} / \mathrm{CO}-23 \mathrm{~d}$, were able to determine the same sample of low $\mathrm{N}_{2} \mathrm{O}$ fluxes with a high mutual coefficient of determination at the $30 \mathrm{~min}$ averaging level and with minor systematic difference over the observation period of several months. This enables us to conclude that the newgeneration instrumentation is capable of measuring small $\mathrm{N}_{2} \mathrm{O}$ exchange with high precision and accuracy at sites with low fluxes.

\section{Introduction}

During the last few years there has been a rapid development in the application of laser spectroscopy for greenhouse gas measurements. In particular, the development of fast response $\mathrm{N}_{2} \mathrm{O}$ analysers based on spectroscopic techniques (e.g. tunable diode laser (TDL) and quantum cascade laser (QCL) spectrometers) has facilitated the eddy covariance (EC) measurements of $\mathrm{N}_{2} \mathrm{O}$ exchange in different ecosystems. Such measurements have been reported in literature and they have been carried out in different ecosystems such as agricultural (Smith et al., 1994; Wienhold et al., 1994; 
Table 1. Instrumental characteristics. Experimental precision values are based on flux measurements during the period DOY 206-271 (period II). TDL - tunable diode laser; CW-QCL - continuous-wave quantum cascade laser; P-QCL - pulsed QCL. $P_{10} / P_{50} / P_{90}$ represent the lower percentile, median and upper percentile values.

\begin{tabular}{|c|c|c|c|c|}
\hline $\begin{array}{l}\text { Instrument } \\
\text { model }\end{array}$ & TGA100A & CW-TILDAS-CS & $\mathrm{N}_{2} \mathrm{O} / \mathrm{CO}-23 \mathrm{~d}$ & QC-TILDAS-76-CS \\
\hline Manufacturer & $\begin{array}{l}\text { Campbell } \\
\text { Scientific Inc. }\end{array}$ & $\begin{array}{l}\text { Aerodyne } \\
\text { Research Inc. }\end{array}$ & $\begin{array}{l}\text { Los Gatos } \\
\text { Research Inc. }\end{array}$ & $\begin{array}{l}\text { Aerodyne } \\
\text { Research Inc. }\end{array}$ \\
\hline $\begin{array}{l}\text { Abbrev. used in } \\
\text { current study }\end{array}$ & CS-TDL & AR-CW-QCL & LGR-CW-QCL & AR-P-QCL \\
\hline Measured species & $\mathrm{N}_{2} \mathrm{O}$ & $\mathrm{N}_{2} \mathrm{O}, \mathrm{H}_{2} \mathrm{O}, \mathrm{CO}$ & $\mathrm{N}_{2} \mathrm{O}, \mathrm{H}_{2} \mathrm{O}, \mathrm{CO}$ & $\mathrm{N}_{2} \mathrm{O}, \mathrm{CO}_{2}, \mathrm{H}_{2} \mathrm{O}$ \\
\hline $\begin{array}{l}\text { Sample cell } \\
\text { volume }(\mathrm{mL})\end{array}$ & 480 & 500 & & $\begin{array}{l}500(76 \mathrm{~m} \\
\text { path length })\end{array}$ \\
\hline $\begin{array}{l}\text { Sample cell } \\
\text { pressure }(\mathrm{hPa})\end{array}$ & 50 & 53 & 117 & 53 \\
\hline $\begin{array}{l}\text { Spectroscopic } \\
\text { correction } \\
\text { coefficient } b\end{array}$ & $\begin{array}{l}0.00 \text { (drier used } \\
\text { in sampling } \\
\text { line) }\end{array}$ & 0.39 & $\begin{array}{l}0.00 \text { (built-in } \\
\text { correction by } \\
\text { the instrument) }\end{array}$ & 0.0235 \\
\hline $\begin{array}{l}\text { Precision, } 10 \mathrm{~Hz} \\
\text { noise } \mathrm{SD}, \\
P_{10} / P_{50} / P_{90} \\
\text { this study (ppb) }\end{array}$ & $1.89 / 1.98 / 2.1$ & $0.12 / 0.12 / 0.14$ & $0.46 / 0.60 / 0.78$ & $0.43 / 0.46 / 0.51$ \\
\hline
\end{tabular}

Christensen et al., 1996; Laville et al., 1997; Scanlon and Kiely, 2003; Neftel et al., 2007; Kroon et al., 2007) and forest (Pihlatie et al., 2005; Eugster et al., 2007), and over urban canopies (Famulari et al., 2010; Järvi et al., 2014).

The observed $\mathrm{N}_{2} \mathrm{O}$ emissions are episodic in nature, showing high spatial and temporal variability. Emission bursts of short duration, typically occurring after fertilizer application, or associated with thawing and rain events (Kroon et al., 2007; Pihlatie et al., 2010), are followed by long periods of small fluxes, when uptake of $\mathrm{N}_{2} \mathrm{O}$ has also been observed (Flechard et al., 2005). Overall, $\mathrm{N}_{2} \mathrm{O}$ fluxes reported by previous studies are characterized by large uncertainties and temporal variability, which are related to biogeochemical soil processes and several systematic and random error sources of the EC measurements. One of the sources of uncertainty for the $\mathrm{N}_{2} \mathrm{O}$ fluxes measured by the EC technique is the performance and stability of fast response gas analysers. Some studies performed under field conditions (Eugster et al., 2007; Kroon et al., 2007; Neftel et al., 2009) have reported that laser drift can cause occasional over- or underestimation of EC flux. Instrumental drift is typically characteristic of TDL as well as QCL spectrometers (Werle et al., 1993; Nelson et al., 2002). Mammarella et al. (2010) thoroughly investigated the performance of TDL instruments in measurements of $\mathrm{N}_{2} \mathrm{O}$ fluxes by the EC technique. They suggested that high-pass filtering could be used to remove the low-frequency signal drifting, which could otherwise con- taminate the detected concentration time series and significantly increase the flux uncertainty.

Apart from episodic emissions, $\mathrm{N}_{2} \mathrm{O}$ fluxes are typically small in magnitude (of the order of 1 to $100 \mu \mathrm{g}$ $\mathrm{N} \mathrm{m}^{-2} \mathrm{~h}^{-1}$, which corresponds to $\mathrm{N}_{2} \mathrm{O}$ flux range from $10^{-2}$ to $1 \mathrm{nmol} \mathrm{m}^{-2} \mathrm{~s}^{-1}$ as presented in the units used in the current study), being on the detection limit of the EC systems (e.g. Pihlatie et al., 2005; Wang et al., 2013). Small fluxes imply small turbulent fluctuations of concentration, requiring high instrument precision to resolve those fluctuations. In other words, the ratio of signal (turbulent fluctuations) to instrumental noise has to be high enough to achieve sufficiently low flux error arising from the noise present in measured signals (Lenschow and Kristensen, 1985).

The goals of this study are to compare the available equipment for $\mathrm{N}_{2} \mathrm{O}$ flux measurements employing the EC technique and to evaluate their performance, ability to detect small fluxes and long-term stability in determining the $\mathrm{N}_{2} \mathrm{O}$ exchange. The instruments used were TGA100A (Campbell Scientific Inc.), CW-TILDAS-CS (Aerodyne Research Inc.), $\mathrm{N}_{2} \mathrm{O} / \mathrm{CO}-23 \mathrm{~d}$ (Los Gatos Research Inc.) and QC-TILDAS76-CS (Aerodyne Research Inc.), which shall be further referred to as CS-TDL, AR-CW-QCL, LGR-CW-QCL and AR-P-QCL, respectively, throughout this study by using the combinations of acronyms for manufacturer and the laser type (see Table 1). In addition, the methods for flux calculation using the laser spectrometer data are evaluated and the 
magnitude and dynamics of $\mathrm{N}_{2} \mathrm{O}$ fluxes during the reed canary grass (RCG) growing season are determined.

\section{Materials and methods}

\subsection{Site}

The measurement site was a 6.9 ha field cultivated with RCG, a perennial bioenergy crop. The site was located in the rural area of Maaninka (merged with the city of Kuopio 1 January 2015), eastern Finland $\left(63^{\circ} 9^{\prime} 48.69^{\prime \prime} \mathrm{N}, 27^{\circ} 14^{\prime} 3.29^{\prime \prime} \mathrm{E}\right)$. Long-term (reference period 1981-2010; Pirinen et al., 2012) annual air temperature in the region is $3.2{ }^{\circ} \mathrm{C}$, the coldest month of the year is February and the warmest is July, with monthly mean air temperature being -9.4 and $17.0^{\circ} \mathrm{C}$, respectively. The annual precipitation in the region is $612 \mathrm{~mm}$. Part of this precipitation amount falls as snow. Snow cover season starts in October and lasts until the end of April with a maximum snow cover of approximately $50 \mathrm{~cm}$. The RCG crop at the Maaninka site was fertilized in the beginning of the growing season (late May), resulting in a large emission pulse of $\mathrm{N}_{2} \mathrm{O}$. The site was applied with an N-P-K-S fertilizer containing $76 \mathrm{~kg} \mathrm{Nha}^{-1}$, based on ammonium nitrate $\left(\mathrm{NO}_{3}-\mathrm{N} / \mathrm{NH}_{4}-\mathrm{N}=47: 53\right)$. The canopy height developed throughout the growing season from about $10 \mathrm{~cm}$ in mid-May to $1.7 \mathrm{~m}$ by late June. The increase in plant height was almost linear in the period between these two times, and from July onwards plant height grew slowly up to $1.9 \mathrm{~m}$.

The soil at the study site is classified as fine sand to coarse silt (particle size $0.03-0.06 \mathrm{~mm}$ ). According to the World Reference Base for Soil Resources (WRB) system (FAO, 2006), the soil is classified as Regosol. The soil $\mathrm{pH}$ varies from 5.4 to 6.1 within the ploughing depth from the surface to about $30 \mathrm{~cm}$, electrical conductivity between 960 and $3060 \mu \mathrm{sm}^{-1}$ and soil organic matter content between 3 and $11 \%$. The average $\mathrm{C} / \mathrm{N}$ ratio in the ploughing depth is 14.9 (ranging from 14.1 to 15.7). The soil particle density is about $2.65 \mathrm{~g} \mathrm{~cm}^{-3}$ within the soil depth from the surface to about $20 \mathrm{~cm}$.

\subsection{Measurements}

Measurements were conducted by the University of Helsinki (UH) and by the University of Eastern Finland (UEF), operating separate EC systems based on two different sonic anemometers. The UH measurement set-up included a 3-D ultrasonic anemometer (USA-1, METEK GmbH, Elmshorn, Germany) to acquire the wind components. The anemometer was installed on top of a pole, with a measurement height of $2.2 \mathrm{~m}$. The measurement height was raised to $2.4 \mathrm{~m}$ on 30 June 2011 due to the RCG growth. The gas analysers were situated in an air conditioned cabin located about $15 \mathrm{~m}$ east from the anemometer pole. This wind direction (50$110^{\circ}$ sector) was therefore discarded from further analysis due to possible disturbances to flux measurements. Sam- ple inlets for gas analysers were located $10 \mathrm{~cm}$ below the anemometer. The $\mathrm{N}_{2} \mathrm{O}$ instruments operated by the $\mathrm{UH}$ were the instrument based on tunable diode laser CS-TDL (model TGA100A, Campbell Scientific Inc.) and two instruments based on continuous-wave quantum cascade lasers, AR-CWQCL (models CW-TILDAS-CS, Aerodyne Research Inc., see e.g. Zahniser et al., 2009; Lee et al., 2011) and LGRCW-QCL (model $\mathrm{N}_{2} \mathrm{O} / \mathrm{CO}-23 \mathrm{~d}$, Los Gatos Research Inc., see e.g. Provencal et al., 2005). Sampling lines of AR-CWQCL and LGR-CW-QCL were heated slightly above ambient temperature in order to prevent water condensing on the lines. CS-TDL used a dryer just before the instrument and no sampling line heating was used. The flow rates and tube dimensions were chosen to correspond to a turbulent flow regime except that the larger diameter of the sampling line of the LGR-CW-QCL analyser resulted in a laminar tube flow for that instrument (see Sect. 3.1 below). Further details of the instruments used are given in Table 1 and details of the different set-ups are given in Table 2.

The maintenance of CS-TDL was the most demanding of the compared instruments. It uses liquid nitrogen to keep the laser source at the operating temperature, and the Dewar was filled up twice a week. The instrument CS-TDL was calibrated in the beginning of the campaign. Further, the operating parameters of the analyser, such as laser current and laser, housing and detector temperatures, were checked once a week and after power failures. In addition, the shape and intensity of the absorption line were checked at the same time. These checks were assumed to guarantee calibration stability of the instrument to a reasonable degree. In addition, the inlet filter of CS-TDL was changed once a month.

The AR-CW-QCL was calibrated and its operating parameters were fine-tuned at the site after instrument installation. The instrument manufacturer provided a software upgrade during the campaign to conduct the real-time water vapour correction to the trace gas concentration data analysed by the instrument. In addition, the operating parameters were fine-tuned a few times on-line by the instrument manufacturer during the campaign.

LGR-CW-QCL was used in the campaign later (see Sect. 2.6 for details). The factory calibration of LGR-CWQCL was checked but no deviation was observed within the uncertainty range of the calibration gases. After about 2 weeks of operation, the laser drifted out of the tuning range and the laser offset current was tuned manually to enable correct operation again. No calibration of the instruments AR-CW-QCL and LGR-CW-QCL was performed during the campaign as these analysers were expected to be very stable according to manufacturers' information.

The UEF set-up included a pulsed quantum cascade laser spectrometer AR-P-QCL (model QC-TILDAS-76-CS, Aerodyne Research Inc., Billerica, MS, USA, see McManus et al., 2005), an infrared gas analyser (IRGA, model Li-6262) and a 3-D sonic anemometer (model R3-50, Gill Instruments, Ltd., Hampshire, UK) for fast response gas concentration and 
Table 2. Eddy covariance measurement set-up, flux calculation and quality screening parameters.

\begin{tabular}{lrrrr}
\hline Instrument & CS-TDL & AR-CW-QCL & LGR-CW-QCL & AR-P-QCL \\
\hline Sampling height (m) & $2.2 / 2.4$ & $2.2 / 2.4$ & 2.4 & $2.0 / 2.5$ \\
Horizontal & 0.05 & 0.05 & 0.07 & 0.1 \\
$\begin{array}{l}\text { separation } \\
\text { Tube inner }\end{array}$ & & & & \\
diameter (mm) & 4 & 4 & 8 & 4 \\
Tube length (m) & 17.8 & 16 & 16 & 8.5 \\
$\begin{array}{l}\text { Flow rate (LPM) } \\
\text { Lag time }\end{array}$ & 17 & 13.2 & 11.6 & 13.5 \\
from tube flow (s) & 0.79 & 0.91 & 4.2 & 0.48 \\
Lag time window & $1.0 \pm 0.0$ & $1.0 \pm 0.0$ & $1.0 \pm 0.0^{2}$ & $1.0 \pm 0.8^{3}$ \\
used in flux & & & & \\
calculation (s) & & & & \\
Time constant & 0.12 & 0.07 & 0.26 & 0.15 \\
used in spectral & & & & \\
corrections (s) & & & & \\
\hline
\end{tabular}

\footnotetext{
${ }^{1}$ Refers to separation of the sampling inlet from the centre position of the sonic anemometer. Vertical separation was $0.1 \mathrm{~m}$ for all instruments. ${ }^{2}$ Prior to flux calculation the concentration records of LGR-CW-QCL were synchronized with AR-CW-QCL outputs. ${ }^{3}$ The lag time window was used to determine the lag time for $\mathrm{CO}_{2}$, which was assigned as the lag time for $\mathrm{N}_{2} \mathrm{O}$.
}

wind component measurements (Tables 1 and 2). The heated intake tubes for the laser spectrometer and IRGA were installed on either side of the sonic anemometer, all mounted on a boom on an adjustable instrument mast. The mast height was set at $2.0 \mathrm{~m}$ above the soil surface in the beginning of the campaign. To adjust to the increasing plant height, the mast was raised to $2.5 \mathrm{~m}$ during mid-June. AR-P-QCL was set up to measure the $\mathrm{N}_{2} \mathrm{O}, \mathrm{CO}_{2}$ and water vapour mixing ratios simultaneously, while the IRGA was used to monitor the $\mathrm{CO}_{2}$ and water vapour mixing ratios. Both trace gas analysers were calibrated against standard gases a minimum of once a month during the campaign; in particular, AR-P-QCL was calibrated every 2-3 weeks with two standard gases of 299 and $342 \mathrm{ppb}$. The calibration slope of AR-P-QCL did not change by more than $7.6 \%$ throughout the campaign and maximum $6.1 \%$ between consecutive calibrations. Thus, $6.1 \%$ can be considered as the maximum flux systematic error arising from calibration accuracy of this instrument.

A weather station set up on another mast close to the EC mast monitored the supporting meteorological variables. The weather station mast height was also adjusted according to the changes in the EC mast height. Supporting measurements included air temperature and relative humidity (model: HMP45C, Vaisala Inc.) using radiation shield, atmospheric pressure (model CS106 Vaisala PTB110 Barometer), wind speed and direction (model 03002-5, R.M. Young Company) and several other variables not used in the current study. Data were collected using a datalogger (model CR3000, Campbell Scientific Inc.). Except air pressure (stored as hourly averages), meteorological data were stored as $30 \mathrm{~min}$ averages. Short gaps in the data were filled using linear interpolation, but when air temperature, relative humidity, pressure or rainfall data were missing for longer periods, data from Maaninka weather station operated by the Finnish Meteorological Institute located about $6 \mathrm{~km}$ south-east from the site were used.

\subsection{Flux processing}

Measurements were sampled at $10 \mathrm{~Hz}$ frequency. In order to eliminate spikes, filtering was performed according to the standard approach (Vickers and Mahrt, 1997), where the high-frequency EC data were de-spiked by comparing two adjacent measurements. If the difference between two adjacent concentration measurements of $\mathrm{N}_{2} \mathrm{O}$ was greater than $20 \mathrm{ppb}$, the following point was replaced with the same value as the previous point.

The spectroscopic correction due to water vapour impact on the absorption line shape was applied along with the Webb-Pearman-Leuning (WPL) dilution correction due to water vapour on high-frequency raw concentration output $X_{\mathrm{C}}$ (mixing ratio with respect to moist air, uncorrected for spectroscopic effect) according to $\chi_{\mathrm{C}}=\frac{\chi_{\mathrm{C}}}{1-(1+b) \chi_{\mathrm{V}}}$. Here $\chi_{\mathrm{C}}$ and $\chi_{\mathrm{V}}$ are the instantaneous mixing ratios of $\mathrm{N}_{2} \mathrm{O}$ and water vapour with respect to dry air. The spectroscopic correction coefficient $b$ was determined experimentally for each instrument (Table 1) by measuring the response of the instrument (output $X_{\mathrm{C}}$ ) to sample air of standard gas (constant $\chi_{\mathrm{C}}$ ) with varying water content $\chi_{\mathrm{V}}$. The correction was not necessary for CS-TDL as a dryer installed after the air intake point on the sampling line dried the air sample before the optical cell. LGR-CW-QCL corrected for the water vapour effect using a built-in module in the LGR data acquisition software; 
the same applied to AR-CW-QCL after a software update in July 2011.

Prior to calculating the turbulent fluxes, a 2-D rotation (mean lateral and vertical wind equal to zero) of sonic anemometer wind components was done according to Kaimal and Finnigan (1994) and all variables were linearly de-trended. The EC fluxes were calculated as 30 min covariances between the scalars and vertical wind velocity following commonly accepted procedures (e.g. Aubinet et al., 2000). Time lag between the concentration and wind measurements induced by the sampling lines was determined by maximizing the covariance. For CS-TDL, the lag was determined by maximizing the covariance for the high flux period only (day of year (DOY) 144-146) because in other periods the lag was not well defined by using this method. The final processing (instruments CS-TDL, AR-CW-QCL and LGR-CW-QCL) was done by fixing the time lag to avoid unphysical variations of lag due to random flux errors. For the AR-P-QCL system, the lag was determined by maximising the covariance for $\mathrm{CO}_{2}$, and the same lag was assigned to $\mathrm{N}_{2} \mathrm{O}$. This was to use the instrument's ability to also measure $\mathrm{CO}_{2}$, therefore enabling the use of a much better signal-to-noise ratio for determinating lag time. Spectral corrections were applied to account for the low- and highfrequency attenuation of the covariances (Sect. 2.4). Then, the humidity effect on temperature flux was accounted for after Schotanus et al. (1983). All data processing was performed with post-processing software EddyUH (http://www. atm.helsinki.fi/Eddy_Covariance/EddyUHsoftware.php).

\subsection{Spectral corrections}

Low- and high-frequency variations in the measured signal are attenuated due to data acquisition and processing, and by a non-ideal measurement system (e.g. Moore, 1986; Moncrieff et al., 1997; Rannik and Vesala, 1999; Massman, 2000). Block averaging and de-trending of data acts as a high-pass filter, thus damping low-frequency changes (Rannik and Vesala, 1999; Finnigan et al., 2003). Turbulent fluctuations occurring at high frequencies are attenuated due to the measurement system's limitations. Gas analyser's finite frequency response, attenuation of fluctuations in the sampling line, spatial separation between the anemometer measurement head and sampling line inlet affect the attenuation of high-frequency fluctuations in the signal.

The observed flux $\left(F_{\mathrm{m}}\right)$ can be formally presented as the integral over the convolution of the true co-spectrum (Co, unaffected by frequency attenuation) with the co-spectral transfer function as

$$
F_{\mathrm{m}}=\int_{0}^{\infty} T(f) \operatorname{Co}(f) \mathrm{d} f
$$

where the co-spectral transfer function $T(f)$ can be presented as the convolution of respective low-frequency $T_{\mathrm{L}}(f)$ and high-frequency $T_{\mathrm{H}}(f)$ transfer functions. For details on the low-frequency transfer function due to high-pass filtering and/or finite averaging period, see Rannik and Vesala (1999).

For evaluation of the instrument frequency performance and subsequent high-frequency flux corrections during postprocessing, the high-frequency transfer function of the EC system was estimated (Aubinet et al., 2000) as the ratio of the observed and un-attenuated flux (Horst, 1997). The cospectral transfer function $T_{\mathrm{H}}(f)$ for a system behaving as a first-order response sensor can be described by

$T_{\mathrm{H}}(f)=\frac{1}{1+(2 \pi f \tau)^{2}}$,

where $f$ is the natural frequency and $\tau$ the (first-order) response time of the attenuator (sensor or the system in total) (Horst, 1997). The effective transfer function of the EC system for different instruments was estimated as the ratio of co-spectral density of scalar flux relative to co-spectrum of sensible heat flux (Aubinet et al., 2000). Such a procedure assumed that temperature measurements were not affected by attenuation (true for the sonic anemometer) and includes normalization with integral over frequencies not affected by attenuation.

\subsection{Estimation of random errors}

Turbulent fluxes averaged over a limited time period have random errors because of the stochastic nature of turbulence (Lenschow et al., 1994; Rannik et al., 2006) as well as due to noise presented in measured signals (Lenschow and Kristensen, 1985).

The random error of the flux was evaluated as 1 standard deviation of the covariance error, hereafter in the manuscript denoted by $\delta_{\mathrm{F}}$. It was defined through the variance of the distribution of the individual flux realization around the ensemble mean (e.g. Lenschow et al., 1994). Theoretically, there are several approaches to approximate the same error estimate; see e.g. Rannik et al. (2009). Currently, the flux random error was calculated according to the method implemented in EddyUH, the method proposed by Finkelstein and Sims (2001). The method evaluates the error in the time domain through integration of the auto-covariance and crosscovariance functions of the vertical wind speed and the scalar concentration according to

$\delta_{\mathrm{F}} \approx \sqrt{\frac{1}{n}\left[\sum_{p=-m}^{m} \overline{w^{\prime} w^{\prime}}(p) \overline{c^{\prime} c^{\prime}}(p)+\sum_{p=-m}^{m} \overline{w^{\prime} c^{\prime}}(p) \overline{c^{\prime} w^{\prime}}(p)\right]}$,

where $\overline{w^{\prime} w^{\prime}}(p)=\frac{1}{n} \sum_{i=1}^{n-p}\left(w\left(t_{i}\right)-\bar{w}\right)\left(w\left(t_{i+p}\right)-\bar{w}\right)$. In calculations, we used $m=200$ (corresponding to 20 s) to ensure that integration of the covariance functions was performed over times exceeding the integral timescale of turbulence. This mathematically rigorous method provides estimates for 
the random uncertainty of the flux measurements for every flux averaging period.

Random uncertainty of the observed covariance due to presence of noise in instruments signal, giving essentially the lowest limit of the flux that the system is able to measure, was expressed in its simplest form as

$\delta_{\mathrm{F}, \text { noise }}=\frac{\sigma_{\mathrm{w}} \sigma_{\text {noise }}}{\sqrt{f T}}$,

where $\sigma_{\mathrm{w}}$ and $\sigma_{\text {noise }}$ denote the standard deviation of the turbulent record of vertical wind speed and the standard deviation of instrumental noise as observed at frequency $f$, and $T$ denotes the flux averaging period. The expression above assumes that the noise component of the vertical wind speed measurement is negligible. In this study, we use the method developed by Lenschow et al. (2000) and applied to EC fluxes by Mauder et al. (2013) to estimate the flux error due to instrumental noise. Lenschow et al. (2000) derived the method to estimate the instrumental random noise variance $\left(\sigma_{\text {noise }}\right)^{2}$ from the auto-covariance function of the measured turbulent record close to zero-shift, enabling one to determine the error for each half-hour flux averaging period.

The random flux error $\delta_{\mathrm{F}}$ is the result of limited sampling in time and/or in space of a stochastic turbulence realization. Its expression includes the covariance and cross-covariance functions of turbulent records; it therefore, in addition to variances and covariances, accounts for the respective integral timescales of turbulent records. The error $\delta_{\mathrm{F}}$ also incorporates the contribution due to instrumental noise and is therefore larger than $\delta_{\mathrm{F} \text {,noise }}$.

The error $\delta_{\mathrm{F} \text {,noise }}$ instead does not depend on the integral timescale of turbulence; it is therefore mainly determined by the instrumental noise characteristics and less by the observation conditions (only via $\sigma_{\mathrm{w}}$ ). Assuming no true turbulent variation of concentration and thus zero flux, the calculated flux will be generally non-zero due to noise in the instrumental signal. Evidently the system will not be able to detect the fluxes smaller than the ones obtained from the expression for $\delta_{\mathrm{F}, \text { noise }}$. Therefore, this is the minimum flux that the EC system can detect and $\delta_{\mathrm{F}, \text { noise }}$ proves useful in characterising the instrumental limitation to detect small fluxes.

If an average over fluxes $F_{i}(i=1 \ldots N)$ is calculated, each of these representing a flux value observed over averaging period $T$ and being characterized by an error $\delta_{F, i}$, then the error of the average flux $\langle F\rangle=\frac{1}{N} \sum_{i=1}^{N} F_{i}$ is expressed as

$\Delta_{<F>}=\sqrt{\frac{\sum_{i=1}^{N}\left(\delta_{F, i}\right)^{2}}{N^{2}}}$.

This expression will be used to estimate the random errors of the average fluxes in Sect. 3.4.

\subsection{Periods of analysis and quality screening}

The intercomparison measurements were performed from the beginning of the growing season in April until Novem- ber 2011. According to instrumental data coverage, the period was divided into three sub-periods for the instrument evaluation and flux analysis purposes. During period I, DOY 110-181 (20 April-30 June 2011), the measurements of CS-TDL, AR-CW-QCL and AR-P-QCL were available; during period II, DOY 206-271 (25 July-28 September 2011), all instruments were measuring; and during period III, DOY 272-324 (29 September-20 November 2011), all other except CS-TDL were operational. Prior to analysis data quality screening was performed. The measurements corresponding to wind direction interval $50-110^{\circ}$ were excluded as possibly affected by the instrumental cabin. In addition, quality screening was performed according to Vickers and Mahrt (1997) by applying the following statistics and selection thresholds: data with $\mathrm{N}_{2} \mathrm{O}$ concentration skewness outside $(-2,2)$, kurtosis outside $(1,8)$ or Haar mean and Haar variance exceeding 3 were rejected. Applying the same statistics and thresholds as for $\mathrm{N}_{2} \mathrm{O}$, additional quality screening of $\mathrm{N}_{2} \mathrm{O}$ fluxes was performed according to $\mathrm{H}_{2} \mathrm{O}$ concentration statistics for AR-CW-QCL and AR-P$\mathrm{QCL}$ due to the impact of the spectroscopic and dilution corrections on fluxes and according to $\mathrm{CO}_{2}$ concentration statistics for AR-P-QCL because the lag obtained for $\mathrm{CO}_{2}$ was assigned to $\mathrm{N}_{2} \mathrm{O}$ in the case of this instrument.

The applied quality criteria were used to ensure exclusion of the system malfunctioning as well as unphysical and/or unusual occasions. No quality screening for stationarity was performed as the focus of the study was the instrumental intercomparison, which was not affected by occasional nonstationary conditions included in the analysed data set.

\section{Results}

The fluxes obtained for three periods are presented in Fig. 1, being averaged over daily period for the clarity of presentation. No gap-filling was used and for each day only the existing measurements, after applying the data quality screening described above, were averaged. In May, the fluxes increased significantly after fertilization and then decreased back to a low, although clearly positive, level after a few weeks. This was the only occasion of high $\mathrm{N}_{2} \mathrm{O}$ emission followed by continuous decrease of fluxes towards the autumn. The soil temperature had an increasing trend until about DOY 205 (24 July 2011) and since August declining seasonal trend (Fig. 2). Soil water content (SWC) increased with occasional rain events. During the high emissions, starting on DOY 144 (24 July 2011) and lasting until approximately DOY 155 (4 June 2011), the SWC was relatively high at approximately $0.3 \mathrm{~m}^{3} \mathrm{~m}^{-3}$.

The high fluxes observed during that period enable us to evaluate the frequency performance of three systems including CS-TDL, AR-CW-QCL and AR-P-QCL. The LGR-CWQCL instrument was not operational then and the frequency 

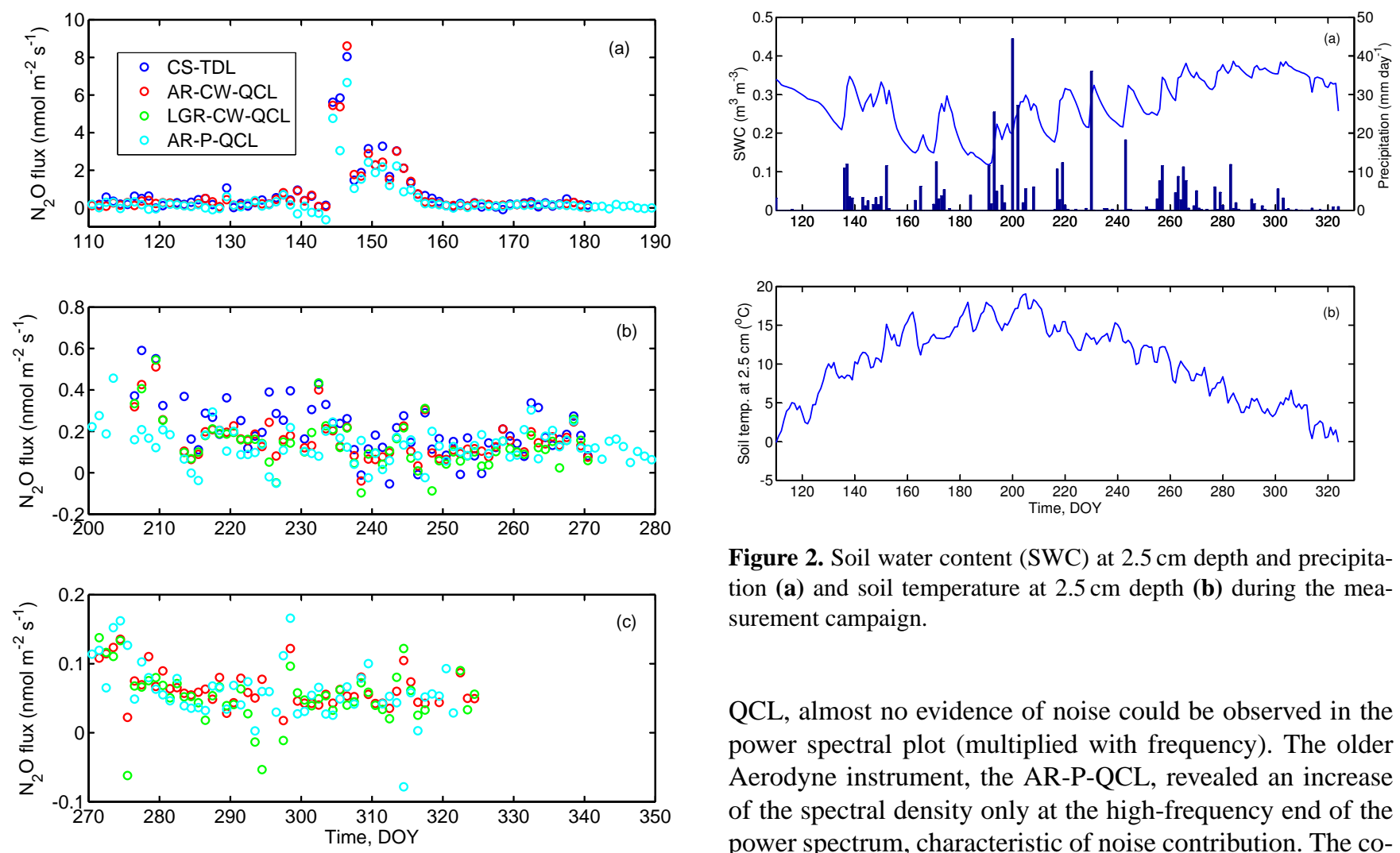

Figure 1. Daily average fluxes for four instruments containing period I DOY 110-181 (a), period II DOY 206-271 (b) and period III DOY 272-324 (c). No gap-filling was used in the calculation of daily average fluxes.

response analysis for this instrument was performed based on the concurrently measured $\mathrm{H}_{2} \mathrm{O}$ and $\mathrm{CO}$ signal analysis.

\subsection{Spectral characteristics of the instruments}

Spectral analysis was performed to study the frequency performance of the instruments. In general, averaging over long periods should lead to better spectral statistics. However, aggregating over different periods might lead to biased results as the spectra do not necessary follow the idealized normalizations in frequency scale, considering also that spectral scaling depends on stability. Therefore, we aimed to use optimal averaging period over several hours for similar conditions in terms of wind speed and stability. For the period of 26 May from 7:00 to 13:00 EET (eastern European time) when the conditions were moderately unstable (average wind speed of the period $3.2 \mathrm{~m} \mathrm{~s}^{-1}$ and sensible heat flux $50 \mathrm{~W} \mathrm{~m}^{-2}$ ), the calculated spectra exhibited very clear and systematic patterns for temperature as well as $\mathrm{N}_{2} \mathrm{O}$ concentration records measured by the three instruments (Fig. 3). In spite of high fluxes registered by the instruments during this period, the CS-TDL $\mathrm{N}_{2} \mathrm{O}$ signal was dominated by noise almost over the whole frequency range presented. For AR-CW-

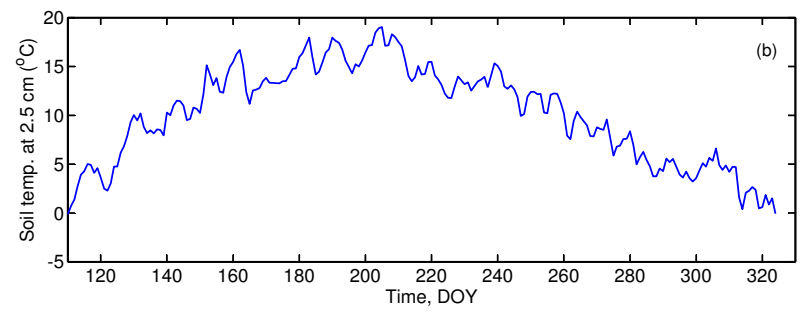

Figure 2. Soil water content $(\mathrm{SWC})$ at $2.5 \mathrm{~cm}$ depth and precipitation (a) and soil temperature at $2.5 \mathrm{~cm}$ depth (b) during the measurement campaign.

QCL, almost no evidence of noise could be observed in the power spectral plot (multiplied with frequency). The older Aerodyne instrument, the AR-P-QCL, revealed an increase of the spectral density only at the high-frequency end of the power spectrum, characteristic of noise contribution. The cospectra of all three instruments showed smooth patterns, the shape being consistent with the co-spectral model by Kaimal et al. (1972) but slightly shifted in frequency scale. At the high-frequency ends of the presented co-spectra the $\mathrm{N}_{2} \mathrm{O}$ signal curves deviate from the theoretical as well as from temperature co-spectra, indicating attenuation of signals at high frequencies by the measurement systems.

The same time period was used to estimate the frequency response of the $\mathrm{N}_{2} \mathrm{O}$ eddy covariance systems according to the method described in Sect. 2.4 (Fig. 4). The time constants estimated by making use of the co-spectra presented in Fig. 3 and Eq. (2) for CS-TDL, AR-CW-QCL and AR-P-QCL were $0.12,0.07$ and $0.08 \mathrm{~s}$, respectively. Note that these time constants characterise the frequency response of the systems in total.

Although the response time obtained for the AR-P-QCL system from high flux period was $0.08 \mathrm{~s}$, the analysis of the response time from measured $\mathrm{CO}_{2}$ signal for several other periods yielded the average response time $0.15 \mathrm{~s}$. The $\mathrm{N}_{2} \mathrm{O}$ signal was synchronized with $\mathrm{CO}_{2}$ by using the lag determined for $\mathrm{CO}_{2}$ and theoretically the $\mathrm{N}_{2} \mathrm{O}$ response time does not differ from that of $\mathrm{CO}_{2}$ under turbulent tube flow regime; hence we choose the constant value $0.15 \mathrm{~s}$ for co-spectral corrections throughout the campaign for this instrument.

Spectral analysis was also performed for the period when LGR-CW-QCL measurements were available. For comparison purposes, the results of the time period of 4 August from 00:30 to 4:00 EET are presented for AR-CW-QCL and LGRCW-QCL instruments (Fig. 5). The period was chosen with 

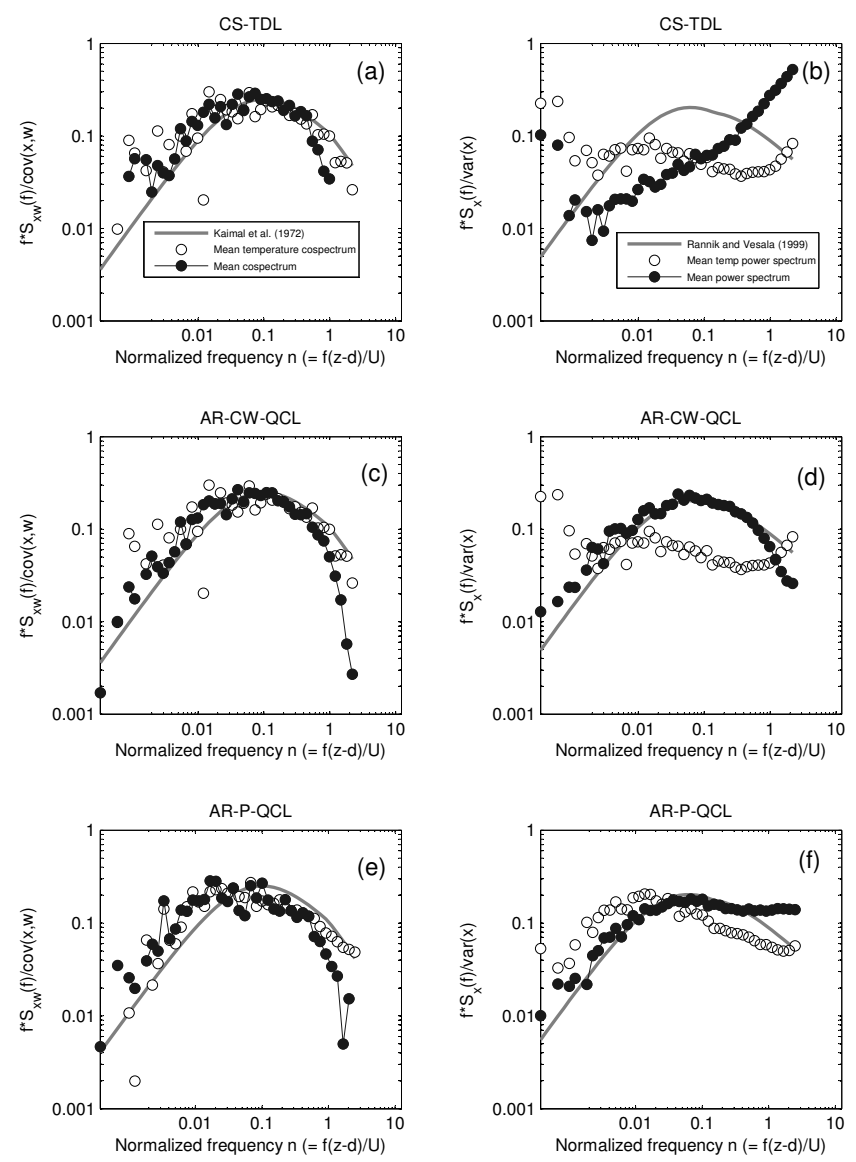

Figure 3. Normalized co-spectra (left panels) and spectra (right panels) of $\mathrm{N}_{2} \mathrm{O}$ measurements by instruments CS-TDL (a, b), ARCW-QCL (c, d) and AR-P-QCL (e, f) during the high flux period, DOY 146 (26 May 2011) 7:00 to 13:00 EET. The RCG crop was about $0.4 \mathrm{~m}$ tall during the given period.

relatively high fluxes (with LGR-CW-QCL measurements available) and similar stability and wind conditions (average wind speed of the period of $0.94 \mathrm{~m} \mathrm{~s}^{-1}$ and sensible heat flux of $-37.5 \mathrm{~W} \mathrm{~m}^{-2}$ ). The power spectra of both instruments revealed a contribution of noise at the high-frequency end of the spectra, which was more pronounced for LGR-CW-QCL. The co-spectra were more scattered when compared to high flux period (Fig. 3). Estimation of the frequency response of the systems based on this period was uncertain due to scatter and could not be used as the basis for co-spectral corrections for LGR-CW-QCL.

The main difference in the flow set-ups of the systems concerned LGR-CW-QCL. With a larger tube diameter and slightly lower flow rate, the flow regime was likely laminar $(\operatorname{Re} \approx 2000)$, whereas for other instruments it was clearly turbulent $(\operatorname{Re} \geq 4600)$. It is well established that under laminar flow regime tube flow attenuates turbulent fluctuations of concentration much more than under turbulent flow. According to the expression for tube attenuation in laminar flow
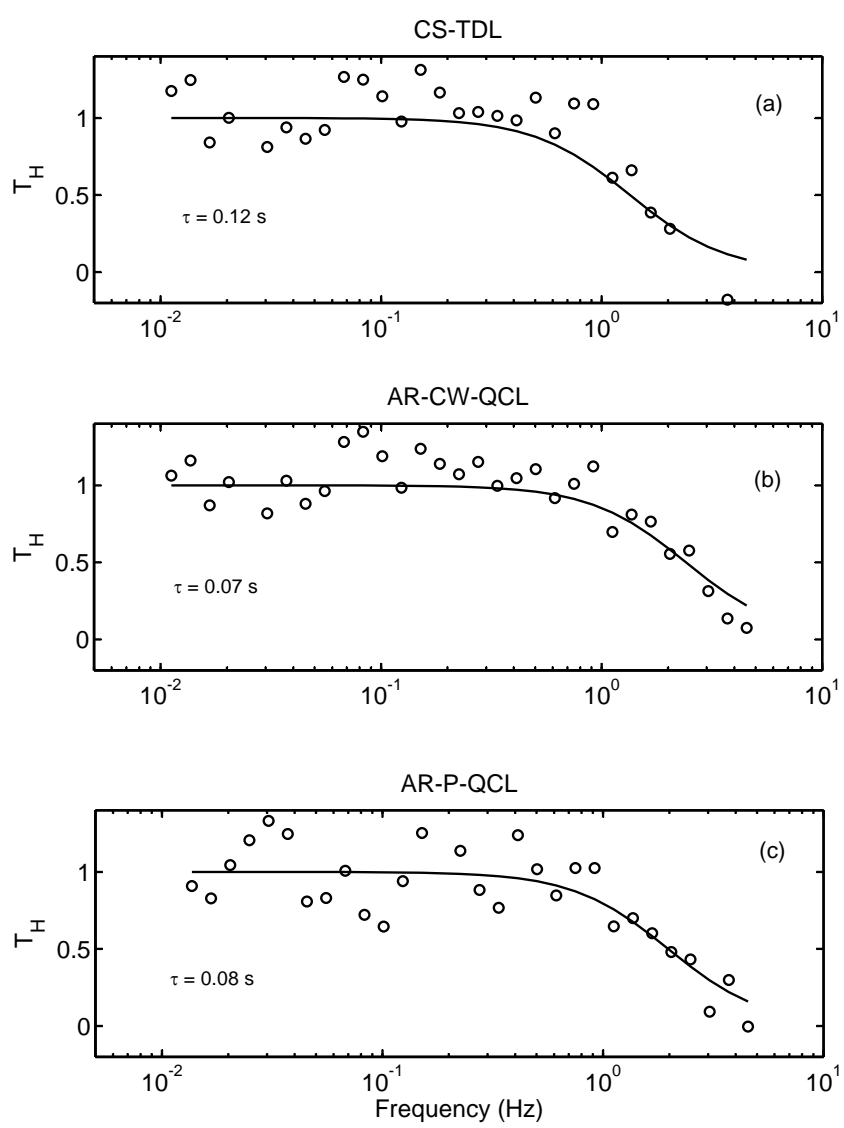

Figure 4. Co-spectral transfer functions derived for CS-TDL (a), AR-CW-QCL (b) and AR-P-QCL (c) from the temperature and $\mathrm{N}_{2} \mathrm{O}$ co-spectra presented in Fig. 2.

regime (Foken et al., 2012) the first-order response time for LGR-CW-QCL flow set-up would be $0.37 \mathrm{~s}$ (estimated for $\mathrm{N}_{2} \mathrm{O}$ ). For turbulent flow (ARI-CW-QCL set-up) the theoretical response time for tube damping is much smaller $(0.01 \mathrm{~s})$ than the response time obtained from the co-spectra $(0.07 \mathrm{~s})$, suggesting that the system's response was dominated by the instrumental response.

The frequency response of the LGR-CW-QCL system was further determined from the co-spectral analysis of the $\mathrm{CO}$ signal, and we obtained the value of $0.26 \mathrm{~s}$. We also determined the experimental response time for water vapour from several periods corresponding to low-humidity conditions $(\mathrm{RH}<40 \%)$ and we consistently found the value around $0.35 \mathrm{~s}$ (for LGR-CW-QCL system). For comparison, the response time for $\mathrm{H}_{2} \mathrm{O}$ measured by the ARI-CWQCL system was determined to be $0.10 \mathrm{~s}$. Damping of water fluctuations in sampling lines is stronger than for other scalars as evidenced by experimental studies (e.g. Mammarella et al., 2009). This is due to adsorption/desorption of water molecules on tube walls. This explains the difference between the response times obtained from $\mathrm{CO}$ and $\mathrm{H}_{2} \mathrm{O}$. Thus, we believe that a value of $0.26 \mathrm{~s}$ characterises well 

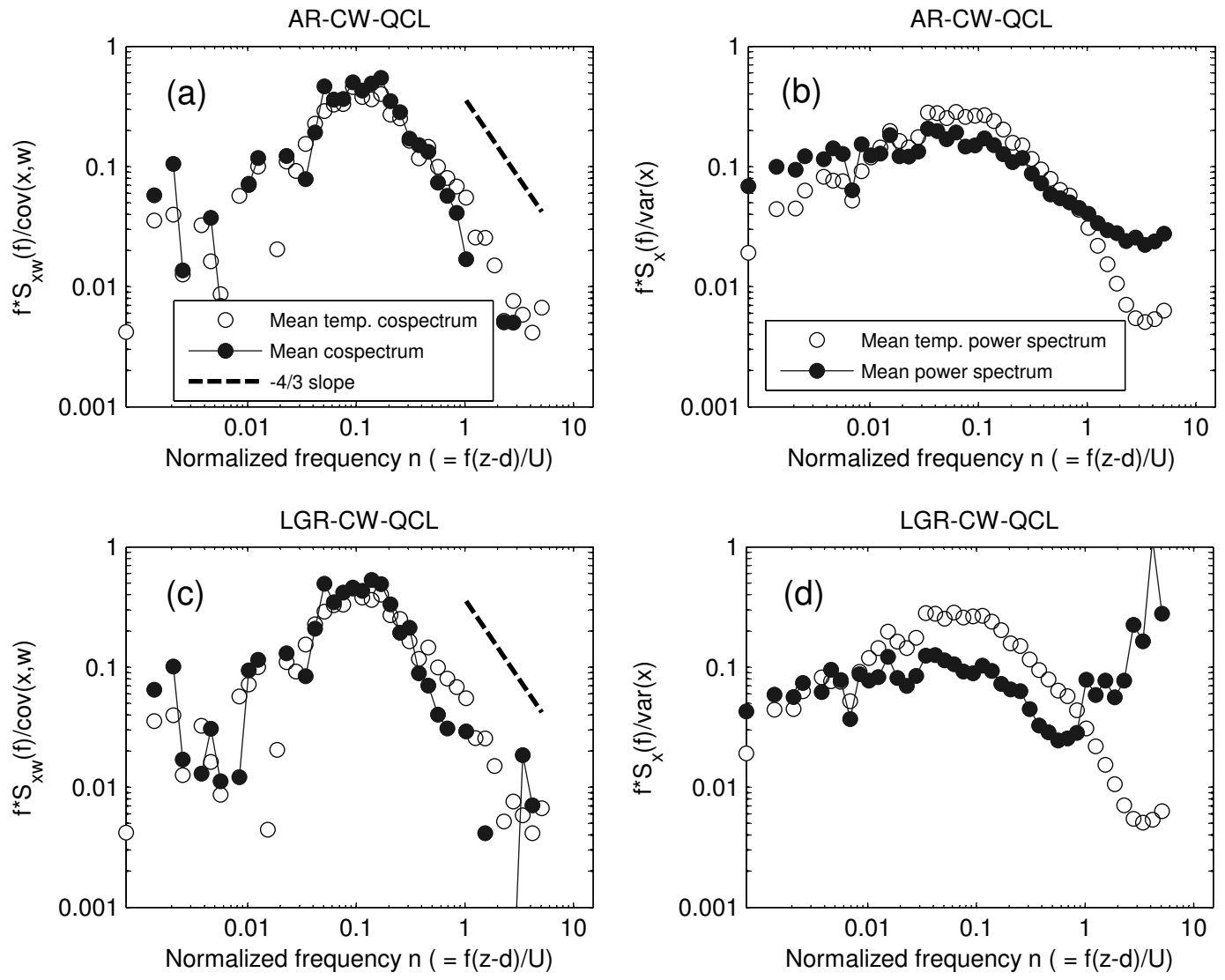

Figure 5. Normalized co-spectra (left panels) and spectra (right panels) of $\mathrm{N}_{2} \mathrm{O}$ measurements by instruments AR-CW-QCL (a, b) and LGR-CW-QCL (c, d) during the period DOY 216 (4 August 2011) 00:30 to 4:00 EET. The RCG crop was about $1.8 \mathrm{~m}$ tall during the given period.

the first-order response time of the LGR-CW-QCL set-up for $\mathrm{N}_{2} \mathrm{O}$, and we use this value in co-spectral corrections. Note, however, that a higher response time of the LGR-CW-QCL system does not mean a slower instrument performance because the system has more damping primarily in the sampling line due to a lower flow rate and larger tube diameter (Table 2).

The frequency response times determined in this section were used in performing the co-spectral corrections (Table 2) as described in Sect. 2.4; the typical magnitudes of these corrections are presented in Table 3.

\subsection{Random uncertainty of fluxes and instrumental noise}

The method by Lenschow et al. (2000) described in Sect. 2.5 enables the calculation of the instrumental noise for each $30 \mathrm{~min}$ period and the resulting flux uncertainty due to instrumental noise. Figure 6a shows the estimated signal's noise statistics with upper and lower percentiles and quantiles (boxes), with a median value in the middle. For all instruments except LGR-CW-QCL, the distributions are very narrow and different percentiles cannot be separated from
Table 3. Statistics of spectral corrections of fluxes as percentage of raw uncorrected fluxes: lower percentile/median/upper percentile. Based on flux measurements during the period DOY 206-271 (period II) and data classified as qualified (Table 4). Daytime was defined by the elevation of sun higher than zero and night-time lower than zero, respectively. Statistics were derived for data when measurements were available for all four instruments.

\begin{tabular}{lrrrr}
\hline & CS-TDL & AR-CW-QCL & LGR-CW-QCL & AR-P-QCL \\
\hline All data & $4.0 / 6.2 / 10.2$ & $2.4 / 3.6 / 6.0$ & $6.9 / 12.3 / 20.0$ & $4.5 / 7.3 / 14.8$ \\
Daytime data & $4.0 / 6.1 / 9.8$ & $2.6 / 3.6 / 5.8$ & $6.9 / 12.0 / 18.5$ & $4.5 / 6.9 / 10.5$ \\
Night data & $3.6 / 6.3 / 11.3$ & $2.2 / 3.6 / 6.4$ & $6.7 / 12.9 / 22.3$ & $4.5 / 7.7 / 20.2$ \\
\hline
\end{tabular}

the plot (for values see Table 1). This tells us that the noise levels of the three instruments are very stable, but the noise level of LGR-CW-QCL somewhat varies. In a comparison of the instruments, AR-CW-QCL has by far the lowest noise level of around $0.12 \mathrm{ppb}$ (standard deviation of the signal's noise at $10 \mathrm{~Hz}$ frequency). The two instruments, LGRCW-QCL and AR-P-QCL, are characterized by a similar noise level (around $0.5 \mathrm{ppb}$ ), while CS-TDL signals show the highest noise level ( $2 \mathrm{ppb})$. Consequently, these instrumental noise levels are reflected in the random errors of 

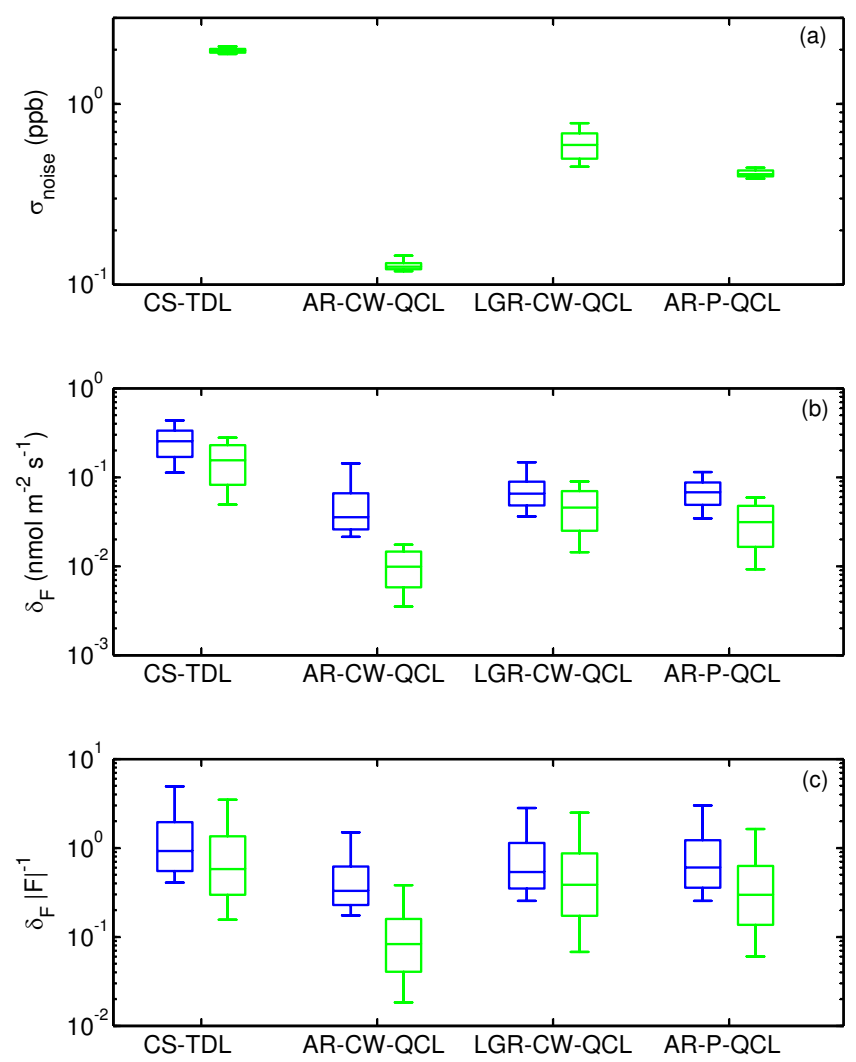

Figure 6. (a) Instrumental noise, presented as 1 standard deviation of the noise at $10 \mathrm{~Hz}$ frequency, (b) $\mathrm{N}_{2} \mathrm{O}$ flux random error (blue) and flux random error due to instrumental noise (green) statistics; (c) the same as (b) but for relative fluxes. The boxplots present the lower and upper percentiles, quartiles and median values of the distributions. Based on flux measurements during the period DOY 206-271 (period II).

fluxes, determining essentially the minimum flux level that each instrument is able to measure at a given flux averaging interval ( $30 \mathrm{~min}$ period). For AR-CW-QCL, the respective lowest flux is around $10^{-2} \mathrm{nmol} \mathrm{m}^{-2} \mathrm{~s}^{-1}$ (as given by median in Fig. 6b), for LGR-CW-QCL and AR-P-QCL around $4 \times 10^{-2} \mathrm{nmol} \mathrm{m}^{-2} \mathrm{~s}^{-1}$ and for CS-TDL $0.15 \mathrm{nmol} \mathrm{m}^{-2} \mathrm{~s}^{-1}$.

The frequency distributions of the total flux random errors, calculated according to Eq. (3), are naturally higher than the flux error due to instrumental noise only. It can be observed that in the case of full flux random error, the difference between different instruments is reduced (Fig. 6b) because in addition to instrumental noise impact, this error statistic also incorporates the flux uncertainty due to the stochastic nature of turbulence. The relative random errors (Fig. 6c) are the largest for CS-TDL (being of the order of $100 \%$ and in most cases less than $\pm 300 \%$ ) and the smallest for AR-CW-QCL instruments (median around $30 \%$ and the error mostly less than $100 \%$ ). It is the signal's noise of the instrument that contributes to the random error of the flux, determining which instrument is able to detect the lowest fluxes. In the case of
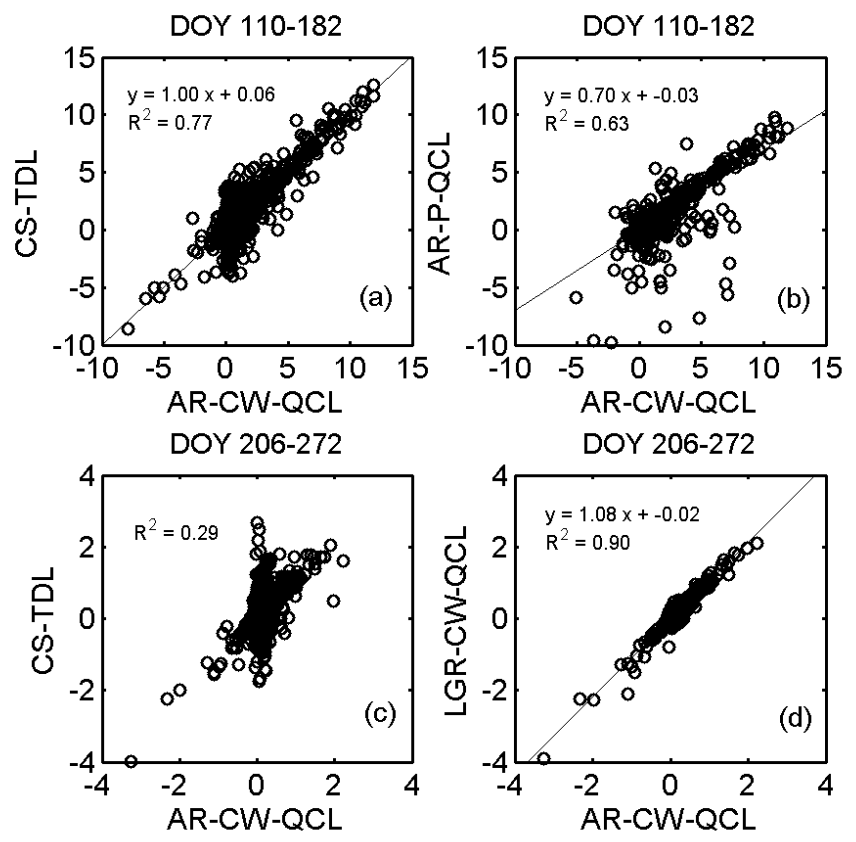

Figure 7. Correlation scatter plots of 30 min average $\mathrm{N}_{2} \mathrm{O}$ fluxes (in $\mathrm{nmol} \mathrm{m}^{-2} \mathrm{~s}^{-1}$ ), as measured by CS-TDL and AR-P-QCL vs. ARCW-QCL during period I DOY 110-181 (a, b), and CS-TDL and LGR-CW-QCL vs. AR-CW-QCL during period II DOY 206-271 (c, d). The lines present the linear fit with coefficients presented on the plots.

CS-TDL the low-frequency signal drifting can also enlarge the total random error of the calculated flux.

\subsection{Intercomparison of fluxes averaged over turbulent spectrum}

It was observed that the fluxes calculated from CS-TDL measurements during the low flux period were dominated by stochastic uncertainty, being frequently of the order of the random uncertainties of the fluxes (Sect. 3.2). Therefore, the fluxes averaged over the $30 \mathrm{~min}$ period were compared for this instrument with AR-CW-QCL results over the period DOY 110-182, which included the high emissions episode starting on DOY 144 and exhibiting elevated fluxes until approximately DOY 155 . In general, the fluxes with high magnitudes obtained by CS-TDL compared well with those of obtained by AR-CW-QCL (Fig. 7a). The AR-P-QCL system, as compared with AR-CW-QCL, showed systematically lower fluxes during the given period of high fluxes (slope 0.70). In spite of the lower noise level of this instrument, the coefficient of determination for this instrument $(0.63)$ was lower than that for CS-TDL (0.77) in comparison to the fluxes as measured by AR-CW-QCL.

During the second observation period, when fluxes were much lower, CS-TDL was not able to determine fluxes with sufficiently small error and the correlation with AR-CWQCL at the $30 \mathrm{~min}$ averaging level was very low (Fig. 7c). 

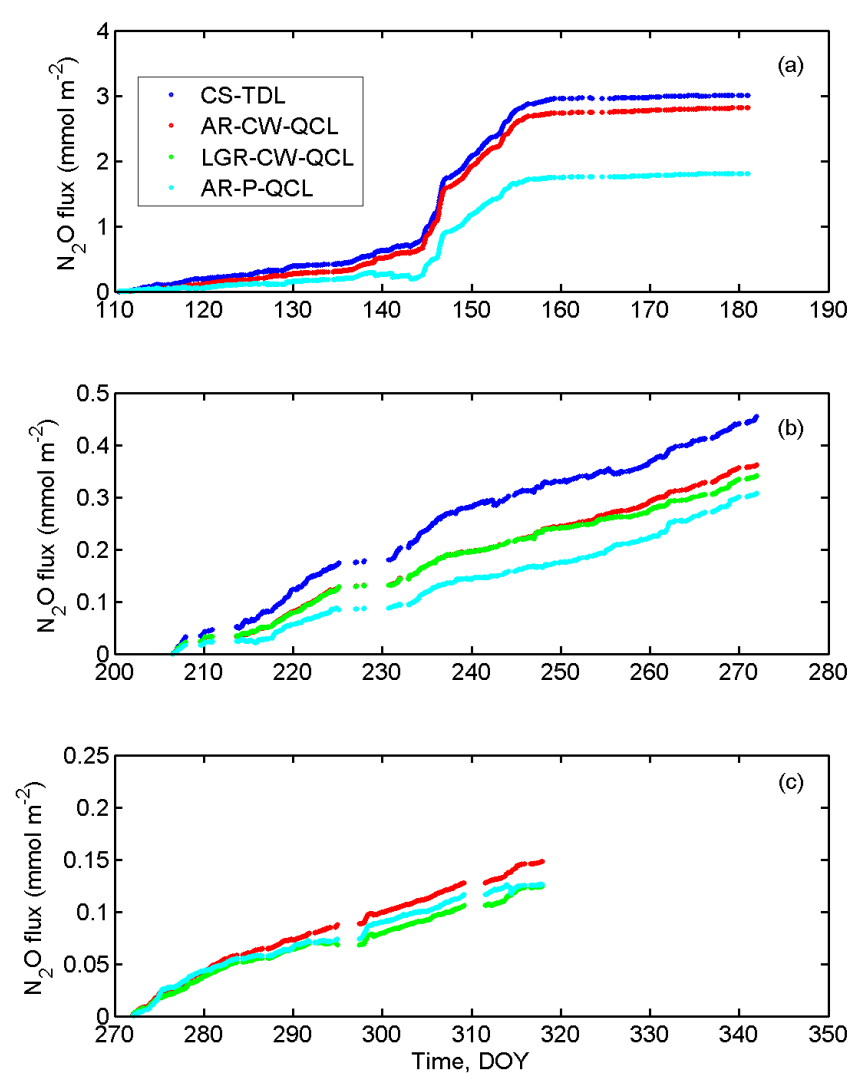

Figure 8. Cumulative sums of available flux data for three periods: (a) period I DOY 110-181 (20 April-30 June 2011), (b) period II DOY 206-271 (25 July-28 September 2011) and (c) period III DOY 272-324 (29 September-20 November 2011). Accumulation of fluxes for each instrument was performed only for data if measurements were available for all instruments used in respective period. No gap filling was used.

At around zero fluxes as measured by AR-CW-QCL, the results of CS-TDL showed scattered values visually between $\pm 2 \mathrm{nmol} \mathrm{m}^{-2} \mathrm{~s}^{-1}$. The noise level of CS-TDL around $2 \mathrm{ppb}$ translates into a flux uncertainty due to instrumental noise of about 0.05 to $0.3 \mathrm{nmol} \mathrm{m}^{-2} \mathrm{~s}^{-1}$. The total flux error $\delta_{\mathrm{F}}$ was within the range of 0.1 to $0.45 \mathrm{nmol} \mathrm{m}^{-2} \mathrm{~s}^{-1}$ (upper and lower quantiles of the distribution in Fig. 6b). We analysed the range of variation of CS-TDL fluxes during the given period DOY 206-272, conditionally selecting the observations when the observed fluxes by AR-CW-QCL were absolutely smaller than $0.15 \mathrm{nmol} \mathrm{m}^{-2} \mathrm{~s}^{-1}$ (90\% of $\mathrm{N}_{2} \mathrm{O}$ flux random errors for AR-CW-QCL less than this value during the given period). The respective $\mathrm{N}_{2} \mathrm{O}$ fluxes as determined by CS-TDL were characterized by the upper and lower quantiles of -0.27 and $0.52 \mathrm{nmol} \mathrm{m}^{-2} \mathrm{~s}^{-1}$. This is consistent with the upper quantile of the flux error distribution for CS-TDL. Therefore, the fluxes of CS-TDL, corresponding to close-tozero fluxes as determined by AR-CW-QCL, were consistent with the flux error estimates.
The comparison of the $30 \mathrm{~min}$ average fluxes calculated from two instruments, AR-CW-QCL and LGR-CW-QCL, revealed very good correspondence and high correlation $\left(R^{2}=\right.$ 0.90 ) even though those measurements corresponded to very low $\mathrm{N}_{2} \mathrm{O}$ fluxes. The slope close to unity and a negligible intercept indicates that there is no systematic bias between the measurements of these systems (Fig. 7d).

\subsection{Long-term averages and systematic differences}

In order to evaluate the possible systematic differences, cumulative curves of the flux observations were calculated. No gap-filling of missing data was done, but instead only the half-hour periods were used when the results for all instruments were available. Thus, the cumulative sums are not assumed to represent the total emissions over the given periods, although rough estimates could be calculated by using the data coverage percentages presented in Table 4 to account for missing flux data. The summation of fluxes over the first and second periods reveals that CS-TDL gives the highest flux sums and AR-P-QCL the lowest, in particular during the first period (Fig. 8). The cumulative sums for fluxes obtained from AR-CW-QCL and LGR-CW-QCL measurements converge over periods II and III and show only small differences. Also, the cumulative fluxes measured by AR-P-QCL during these periods are very close to fluxes measured by the two other instruments. In order to assess the magnitude of the random errors in these differences, the random errors of the fluxes averaged over the three periods were calculated according to Eq. (5). The analysis revealed that the average fluxes for period II, obtained from the measurements of AR-CW-QCL and LGR-CW-QCL instruments, did not differ within calculated error limits, and were very close during period III to the result for AR-P-QCL (Table 4).

However, CS-TDL produced a $7 \%$ higher total sum for the period of high fluxes (DOY 110-181 with an average flux of $0.87 \mathrm{nmol} \mathrm{m}^{-2} \mathrm{~s}^{-1}$ as determined by AR-CW-QCL) and a $29 \%$ higher sum for the second period (DOY 206271) compared to an average flux $0.142 \mathrm{nmol} \mathrm{m}^{-2} \mathrm{~s}^{-1}$ (average of AR-CW-QCL and LGR-CW-QCL results). The AR$\mathrm{P}-\mathrm{QCL}$ instrument determined for these two periods 36 and $13 \%$ lower average fluxes, respectively. The possible reasons for this will be discussed in the next section. For the third period, the results of AR-P-QCL did not differ much from the results of the other two instruments.

\section{Discussion}

Performance of four instruments (see Tables 1 and 2) capable of fast response measurement of $\mathrm{N}_{2} \mathrm{O}$ was studied throughout the 2011 growing season over a field cultivated with RCG in eastern Finland. The $\mathrm{N}_{2} \mathrm{O}$ fluxes were small in the beginning of the season, increased significantly after fertilization (late May) and then decreased back to low, positive values after a 
Table 4. Average fluxes (nmol m${ }^{-2} \mathrm{~s}^{-1}$ ) \pm random error of the average. Period I DOY 110-181 (20 April-30 June 2011), period II DOY 206-271 (25 July-28 September 2011), period III DOY 272-324 (29 September-20 November 2011). Percent data available represents the fraction of half-hour periods when data from all instruments (three in periods I and III and all four in period II) was available (data from wind direction interval $50-110^{\circ}$ excluded), relative to full time period length. Averaging of fluxes for each instrument was performed only for data if measurements were available for all instruments used in respective period. No gap filling was used.

\begin{tabular}{lcccccrrr}
\hline & $\begin{array}{c}\text { \% data } \\
\text { available }\end{array}$ & $\begin{array}{c}\text { \% data qualified } \\
\text { (out of available) }\end{array}$ & $\begin{array}{c}\text { no. of 30 min periods } \\
\text { averaged }\end{array}$ & CS-TDL & AR-CW-QCL & LGR-CW-QCL & AR-P-QCL \\
\hline Period I & 69.2 & 75.2 & 1797 & $0.931 \pm 0.018$ & $0.870 \pm 0.009$ & - & $0.560 \pm 0.011$ \\
Period II & 55.0 & 79.4 & 1383 & $0.183 \pm 0.010$ & $0.146 \pm 0.006$ & $0.138 \pm 0.007$ & $0.124 \pm 0.003$ \\
Period III & 61.4 & 78.2 & 1220 & - & $0.067 \pm 0.002$ & $0.057 \pm 0.002$ & $0.058 \pm 0.003$ \\
\hline
\end{tabular}

few weeks. Three instruments, CS-TDL, AR-CW-QCL and AR-P-QCL were operational during this high emissions period. During this period, all instruments detected the same flux dynamics, whereas the fluxes obtained by AR-P-QCL, the previous instrument version by Aerodyne, were lower compared to the other two instruments.

For many applications, the systematic errors of micrometeorological flux measurements of atmospheric trace gases are more important than the random errors. For example, for determination of annual balances (e.g. Kroon et al., 2010b) or for the comparison of exchange of different ecosystems (e.g. Nicolini et al., 2013) the systematic errors become very important. The two CW-QCL instruments compared very well on a half-hourly basis and produced statistically close cumulative fluxes over the period when the two instruments were simultaneously operational (25 July 2011-20 November 2011). The cumulative emission estimate obtained by CS-TDL for period II (25 July-28 September 2011) was $29 \%$ higher than the average result for instruments based on the continuous-wave quantum cascade lasers, AR-CW-QCL and LGR-CW-QCL. AR-P-QCL obtained $36 \%$ lower fluxes than AR-CW-QCL during the first period including the emission episode, whereas the correspondence with other instruments during the rest of the campaign was relatively good.

The systematic differences in fluxes could be the result of calibration and/or limited stability of the system over time. The impact of the instruments calibration (sensitivity shift) impact on flux systematic differences can be assessed by using calibration information (Sect. 2.2) as well as comparison of average concentrations measured by different instruments. The two analysers based on CW-QCL-s are expected to be very stable, which was confirmed by the measurements: the concentrations measured by these two instruments were very consistent and the slope (characterising sensitivity) of the $30 \mathrm{~min}$ average concentration comparison did not deviate from unity by more than $5 \%$ (with the coefficient of determination of linear regression $R^{2}=0.86$ ).

The sensitivity of AR-P-QCL did not change more than $6.1 \%$ between consecutive calibrations, and this can be considered as the maximum flux error arising from the calibration accuracy of this instrument (Sec. 2.2). Nevertheless, the correlation of the $30 \mathrm{~min}$ average concentration measured by this instrument as compared to AR-CW-QCL was not as good (for the period DOY 206-272, a slope of 1.05 was determined with $R^{2}=0.63$ ). The concentration comparison presented here does not imply that the calibration bias was the reason for the observed flux systematic difference for the instrument AR-P-QCL.

The analyser CS-TDL is known for its signal drifting as illustrated and discussed by Mammarella et al. (2010), and the absolute concentrations were not well determined during our campaign. Therefore, accurate measurement of absolute concentration by this instrument over a long period of time cannot be expected, and the concentration comparison was not used as the method for evaluation of the instrument's calibration impact on flux systematic bias. Note that signal drifting makes the time series produced by the instrument essentially non-stationary and therefore enhances the random variability of the flux estimate around the true value. However, such enhanced random uncertainty does not systematically affect the cumulative sums over longer periods.

In the case of low fluxes the water vapour dilution and spectral line broadening effects are the primary suspects for the reasons in systematic differences in fluxes (e.g. Peltola et al., 2014). Close correspondence of the concentrations and fluxes as measured by AR-CW-QCL and LGR-CW-QCL let us conclude that the spectroscopic and water vapour dilution corrections for these instruments were adequate. Note that those corrections were done by built-in functionality in the case of LGR-CW-QCL. For AR-CW-QCL, the respective corrections were done in post-processing phase for period I and by built-in software for the rest of the campaign.

The only evident systematic flux error source that could affect performance of CS-TDL would be incomplete drying of sample air. If that was the case, then the calculated fluxes would have suffered from missing partial density and spectroscopic corrections. Since the water fluxes are dominantly upward, a respective correction would tend to increase the flux values, therefore increasing even more the systematic difference relative to other instruments.

The instrument ARI-P-QCL is based on the pulsed quantum cascade laser. For this instrument, the experimentally 
Table 5. Average micrometeorological conditions during the experimental periods. Period I DOY 110-181 (20 April-30 June 2011), period II DOY 206-271 (25 July-28 September 2011), period III DOY 272-324 (29 September-20 November 2011). Daytime was defined by the elevation of sun higher than zero and night-time lower than zero, respectively. Average latent heat fluxes were determined from IRGA measurements.

\begin{tabular}{lcccccc}
\hline Temperature & $\begin{array}{c}\text { Air rel. } \\
\text { humidity, } \\
\%\end{array}$ & $\begin{array}{c}\text { Wind } \\
\text { speed, } \\
\mathrm{m} \mathrm{s}^{-1}\end{array}$ & $\begin{array}{c}\text { Friction } \\
\text { velocity, } \\
\mathrm{m} \mathrm{s}^{-1}\end{array}$ & $\begin{array}{c}\text { Sensible } \\
\text { heat flux, } \\
\mathrm{W} \mathrm{m}^{-2}\end{array}$ & $\begin{array}{c}\text { Latent } \\
\text { heat flux, } \\
\mathrm{W} \mathrm{m}^{-2}\end{array}$ \\
\hline Day, I & 11.6 & 62.9 & 2.21 & 0.28 & 27.5 & 78.9 \\
Night, I & 6.5 & 78.3 & 1.34 & 0.14 & -20.2 & 8.1 \\
Day, II & 15.3 & 75.2 & 1.35 & 0.26 & 9.7 & 109.3 \\
Night, II & 11.2 & 90.3 & 1.06 & 0.17 & -18.6 & 10.1 \\
Day, III & 6.1 & 85.0 & 1.46 & 0.29 & -10.8 & 41.5 \\
Night, III & 4.8 & 90.6 & 1.21 & 0.23 & -23.5 & 11.5 \\
\hline
\end{tabular}

determined spectroscopic correction coefficient was much lower than the coefficient for AR-CW-QCL (Table 1). The reason for systematically lower values of fluxes determined by AR-P-QCL from the beginning of the experiment in April until June 2011, but subsequent relatively good comparison with other instruments towards the end of the experiment in November 2011, is not known. Two types of corrections were applied to $\mathrm{N}_{2} \mathrm{O}$ fluxes: the spectroscopic correction to account for the impact of water vapour on the absorption line shape, and the co-spectral correction. The latter correction was comparable to all instruments (Table 3) and does not introduce a significant difference between instruments. The spectroscopic correction was applied together with the water vapour dilution correction (Sect. 2.3) and can constitute a major correction depending on the value of the coefficient $b$. The correction is related to the water vapour flux, which was during the daytime on the average around $100 \mathrm{Wm}^{-2}$ (periods I and II, Table 5), with mid-day averages around 150 to $200 \mathrm{Wm}^{-2}$. Considering an average concentration of $\mathrm{N}_{2} \mathrm{O}$ around $330 \mathrm{ppb}$ and spectroscopic correction value $b=0.39$ (the value for AR-CW-QCL), the spectroscopic correction can be a few tenths of nmol m${ }^{-2} \mathrm{~s}^{-1}$ during mid-day, which is of the order of the flux magnitude. We used all auxiliary data available to investigate the possible reasons for the systematic differences, but found no explaining variable or reason. In particular, no systematic variation of the residual between AR-P-QCL and AR-CW-QCL fluxes was found over wide range of latent heat fluxes from -20 to $250 \mathrm{~W} \mathrm{~m}^{-2}$. This proves that the dilution and spectroscopic corrections were properly accounted for. In addition, larger spectroscopic correction would not explain the systematic difference observed only during the first period.

Thus the reasons for flux underestimation by AR-P-QCL during period I are not known, and we suggest that extreme care should be exercised during long-term measurement campaigns both with $\mathrm{N}_{2} \mathrm{O}$ and $\mathrm{H}_{2} \mathrm{O}$ calibrations due to the strong impact of the water vapour on the $\mathrm{N}_{2} \mathrm{O}$ flux through spectroscopic and dilution corrections.
A comment should be made regarding the observation level used in the study. When RCG was grown high, the measurement level was only about $0.5 \mathrm{~m}$ above the canopy top. The measurements within the roughness sublayer can be disturbed in terms of several statistics, but the impact can be expected to reveal more in spectral shapes than in integral statistics. The spectra obtained for $\mathrm{N}_{2} \mathrm{O}$ (Figs. 3 and 5 ) were dominated by white noise over wider (CS-TDL) or narrow (AR-CW-QCL) frequency ranges depending on the instrument in question. The temperature spectra were similarly affected by the noise but only at the high-frequency end of spectra and we believe do not show evidence of a canopy impact on spectral shapes. We checked also the spectra for vertical wind speed (not shown). The spectra exhibited smooth and consistent shapes, without the particular impact of the canopy foliage on spectral forms usually observed inside canopies. Launiainen et al. (2007) studied the turbulence statistics and spectral shapes within pine forest canopy. They did not observe deviation of spectral shapes above canopy at height $z / h=1.47$ ( $h$ being the canopy height) from the atmospheric surface layer forms; within the crown space $(z / h=0.78)$, the spectra deviated only slightly from the above-canopy forms. Within the trunk space $(z / h=0.4)$, the spectra were distorted due to the drag imposed by the canopy elements. This supports that the spectra measured close to but above canopy are weakly affected by the canopy presence. Thus, we do not expect that the relatively low observation level biases the overall $\mathrm{N}_{2} \mathrm{O}$ flux magnitude and that the comparison of instrumentation is affected. Also, the effect on the instrumental noise and flux random uncertainty analysis is expected to be very limited through the influence on the covariance functions. The positive impact of the close positioning of the system could be its higher sensitivity in detecting the low fluxes through higher concentration fluctuations expected (more) close to the source level.

Important characteristics of the instruments for performing the $\mathrm{EC}$ measurements are the response time and the noise level. The response times for CS-TDL, AR-CW-QCL and AR-P-QCL flux measurements systems were determined to 
be 0.12 and 0.07 and $0.08 \mathrm{~s}$, respectively. The main factors affecting the response time of the closed-path EC system are the damping of fluctuations in the sampling line and the instrumental response. Since the flow rate of the CS-TDL system was higher, it can be concluded that the response characteristics of other two instruments are superior. The response time of the EC system including LGR-CW-QCL was larger due to the laminar tube flow regime, but the instrumental response was not determined based on the current field measurements.

In order to understand drivers of exchange and infer the broad average fluxes such as seasonal or annual sums by using gap-filling methodologies, it is important that the exchange at a shorter timescale is distinguishable from random variation. Therefore, an understanding of random errors is important when working with low fluxes as is frequently the case with $\mathrm{N}_{2} \mathrm{O}$. At the half-hour averaging timescale, the flux estimates for AR-CW-QCL and LGR-CW-QCL instruments were very well correlated and showed good correspondence. Apart from high $\mathrm{N}_{2} \mathrm{O}$ fluxes exceeding a few $\mathrm{nmol} \mathrm{m}^{-2} \mathrm{~s}^{-1}$ during the high emissions period, CS-TDL was not able to resolve the emission fluxes at half-hourly timescale. Therefore, one can conclude that CS-TDL is not suitable for measuring such low fluxes if the aim is to resolve fluxes at hourly timescale and not the daily or longer averages.

Aerodyne AR-CW-QCL had the lowest noise level (around $0.12 \mathrm{ppb}$ at $10 \mathrm{~Hz}$ sampling rate) compared to Los Gatos LGR-CW-QCL instrument (SD of noise $0.60 \mathrm{ppb}$ ) and has therefore an advantage in resolving low fluxes over short averaging periods. The noise level of AR-P-QCL was comparable to LGR-CW-QCL, but the old-generation instrument Campbell CS-TDL suffered clearly from higher noise level (around $2 \mathrm{ppb}$ ). Huang et al. (2014) reported for the instrument similar to AR-CW-QCL the precision $0.066 \mathrm{ppb}$ for $10 \mathrm{~Hz}$. The value obtained by us was higher roughly by a factor of 2 . According to the manufacturer, the precision of LGR-CW-QCL is $0.1 \mathrm{ppb}$ at $1 \mathrm{~Hz}$ averaging; at $10 \mathrm{~Hz}$ this would correspond to $0.32 \mathrm{ppb}$. We have determined again a median value roughly twice higher than this. Kroon et al. (2007) reported for the instrument similar to AR$\mathrm{P}-\mathrm{QCL}$ the precision value of $0.5 \mathrm{ppb} \mathrm{Hz}^{-1 / 2}$ (equivalent to $1.6 \mathrm{ppb}$ at $10 \mathrm{~Hz}$ ), whereas Neftel et al. (2007) and Eugster et al. (2007) report $0.3 \mathrm{ppb} \mathrm{Hz}^{-1 / 2}$ (equivalent to $0.95 \mathrm{ppb}$ at $10 \mathrm{~Hz}$ ). Pihlatie et al. (2005) and Wang et al. (2013) report noise for CS-TDL as $1 \mathrm{ppb}$ and $1.5 \mathrm{ppb}$ (at $10 \mathrm{~Hz}$ ), respectively. Under field conditions the instrumental noise can be somewhat higher compared to laboratory conditions where the instrumental characteristics are typically studied. Also, the estimation method from the field records where the turbulent variation is superimposed by the instrumental noise can introduce some uncertainty. In summary, the observed instrumental noise characteristics for instruments compare well with the results reported by others and are useful in characterising instrumental performance.
The flux errors due to instrumental noise for the observation conditions prevailing at the site were determined to be around $10^{-2} \mathrm{nmol} \mathrm{m}^{-2} \mathrm{~s}^{-1}$ for AR-CW-QCL, $4 \times 10^{-2} \mathrm{nmol} \mathrm{m}^{-2} \mathrm{~s}^{-1}$ for LGR-CW-QCL and AR-P-QCL and $0.15 \mathrm{nmol} \mathrm{m}^{-2} \mathrm{~s}^{-1}$ for CS-TDL. Based on a half-hour and long-term flux comparison, the best correspondence was observed between the systems with the new-generation instruments AR-CW-QCL and LGR-CW-QCL, of which the former has the advantage of detecting lower fluxes at a halfhourly averaging basis (lower noise level).

The signal's noise of the anemometer used by the UH (USA1 by METEK) was determined to be $0.037 \mathrm{~m} \mathrm{~s}^{-1}$ at $10 \mathrm{~Hz}$ sampling frequency for the vertical wind speed component. The noise level of the anemometer employed by the UEF was similar. The flux error due to anemometer's noise for the observation conditions prevailing at the site during the period DOY 206-271 (the period for the statistics presented in Fig. 6) was determined to be around $2 \times 10^{-3} \mathrm{nmol} \mathrm{m}^{-2} \mathrm{~s}^{-1}$ (the median value). This was much less than the respective flux error around $10^{-2} \mathrm{nmol} \mathrm{m}^{-2} \mathrm{~s}^{-1}$ for the instrument AR-CW-QCL, which had the lowest noise level $0.012 \mathrm{ppb}$ (median value) of all instruments compared. Therefore, the assumption that the anemometer's noise affects flux detection much less than the gas analysers was well justified.

The chamber techniques are widely used to measure the soil $\mathrm{N}_{2} \mathrm{O}$ exchange. The traditional way to perform chamber measurements is to determine the gas concentration at several moments during the chamber operation (called deployment time, DT). In such data collection the sources of uncertainty are the imprecision related to gas sampling (either manual or automatic) as well as instrumental uncertainty (e.g. Venterea et al., 2009), leading to a measurement precision which is called the detection limit of chamber-based flux measurement system. Neftel et al. (2007) report a flux detection limit of about $0.23 \mathrm{nmol} \mathrm{m}^{-2} \mathrm{~s}^{-1}$ for their chamber system with DT of $10 \mathrm{~min}$ and the concentration sampling interval of $1 \mathrm{~min}$. The measurement cycle of the system was however $2 \mathrm{~h}$. Wang et al. (2013) found for their automatic and manual chamber systems detection limits of about $5 \mu \mathrm{g} \mathrm{m}^{-2} \mathrm{~h}^{-1}\left(0.05 \mathrm{nmol} \mathrm{m}^{-2} \mathrm{~s}^{-1}\right)$ for hourly DT. Their instrument precision was high, around $0.4 \%$ relative to ambient $\mathrm{N}_{2} \mathrm{O}$ concentration. By using the methodology and scaled results presented by Parkin et al. (2012), we estimated the flux detection limit of a chamber system with an assumed chamber height of $0.5 \mathrm{~m}$, area of $0.25 \mathrm{~m}^{2}$, deployment time $30 \mathrm{~min}$ and instrumental precision as high as $0.1 \%$ to be $0.03 \mathrm{nmol} \mathrm{m}^{-2} \mathrm{~s}^{-1}$. It has to be noted that the flux detection limit of the chamber systems depends on several factors such as the type of the chamber and respective sampling method, the precision of the instrument, chamber dimensions and operation time (DT). Nevertheless, the obtained result is well comparable with the EC systems. The random error of $\mathrm{N}_{2} \mathrm{O}$ fluxes for $30 \mathrm{~min}$ averaging time for the instrument with lowest noise, the AR-CW-QCL instrument, was found to be 
$0.036 \mathrm{nmol} \mathrm{m}^{-2} \mathrm{~s}^{-1}$ (the median value). Note that here we compare the flux detection limit of the chamber-based systems (which accounts for all possible sources of uncertainty) with the total stochastic error of the EC fluxes. The results are of the same magnitude.

In this study we followed the methodology proposed by Mauder et al. (2013) in quantification of the random errors in EC fluxes, i.e. the stochastic error and the error due to instrumental noise in flux. The relative random errors obtained in our study were much larger than the respective errors reported by Mauder et al. (2013) for $\mathrm{CO}_{2}$ measurements, evidencing that the importance of random errors depends on the trace gas of interest via instrumental precision and the flux magnitude ratio. Kroon et al. (2010a) focus on the evaluation of the EC flux measurements of $\mathrm{CH}_{4}$ and $\mathrm{N}_{2} \mathrm{O}$ specifically. They observed over a dairy farm site the fluxes in the range of 15 to $110 \mathrm{ng} \mathrm{N} \mathrm{m}^{-2} \mathrm{~s}^{-1}\left(0.5\right.$ to $\left.4 \mathrm{nmol} \mathrm{m}^{-2} \mathrm{~s}^{-1}\right)$, which they classified in low to high flux classes. They performed calibration of the instrument similar to our AR-P-QCL weekly and considered the respective uncertainty random over longer periods of time. Kroon et al. (2010a) reported the average daily and monthly flux relative uncertainties of 31 and $7 \%$, respectively. In our study the $\mathrm{N}_{2} \mathrm{O}$ fluxes were typically much smaller (excluding the fertilization episode), around 0.1 to $0.3 \mathrm{nmol} \mathrm{m}^{-2} \mathrm{~s}^{-1}$. We measured with the similar instrument $36 \%$ lower fluxes than obtained by AR-CW-QCL over the period DOY $110-181$ and $13 \%$ lower fluxes than obtained by two new-generation instruments over the period DOY 206271. Evidently our measurements performance was affected by an unidentified error source, systematic in nature. In evaluation of the annual balances of $\mathrm{CH}_{4}$ and $\mathrm{N}_{2} \mathrm{O}$ fluxes over a managed fen meadow, Kroon et al. (2010b) made an assumption that the uncertainty in EC fluxes was random and was neglected in the evaluation of long-term averages. In our results, this assumption was contradicted, and we suggest that all possible systematic error sources should be considered very carefully in planning, implementing and evaluating the flux measurements of trace gases.

In analysing the random errors of the fluxes Kroon et al. (2010a) assumed that the flux error due to instrumental precision in concentration measurement was negligible. We observed that this was not necessarily the case for $\mathrm{N}_{2} \mathrm{O}$ when low flux levels were measured and demonstrated that the method originally proposed by Lenchow et al. (2000) to determine instrumental noise variance worked well in field conditions over a long period of time.

\section{Conclusions}

The new instruments based on continuous-wave quantum cascade lasers, AR-CW-QCL and LGR-CW-QCL, were stable throughout of the campaign in terms of determining the absolute concentrations and obtaining close fluxes.

The older instruments CS-TDL and AR-P-QCL measured systematically different fluxes over subperiods of the campaign up to +29 and $-36 \%$, respectively, compared to the new instruments based on CW-QCL-s, whereas the systematic differences did not prevail throughout the campaign. The reasons for the systematic differences were not identified. We suggest that special emphasis should be on the instrumental stability and correcting procedures that can systematically affect the accuracy of measured fluxes when conducting longterm measurements of prevailingly low fluxes.

The lowest noise level was determined for AR-CWQCL $(0.12 \mathrm{ppb}$ at $10 \mathrm{~Hz}$ sampling rate) and the highest for the old-generation instrument CS-TDL (precision $2 \mathrm{ppb}$ at $10 \mathrm{~Hz}$ sampling rate). During the period DOY 206-272, when all instruments were operational, the lower-quantile/median/upper-quantile statistics of the fluxes measured by AR-CW-QCL instrument were $0.008 / 0.11 / 0.31 \mathrm{nmol} \mathrm{m}^{-2} \mathrm{~s}^{-1}$, respectively.

The random errors of fluxes originate from the stochastic nature of turbulence (one-point sampling over limited time interval). Additionally, the instrumental noise contributes to the random flux error. The median values for flux errors during the period DOY 206-272 (error due to instrumental noise/total error) were detected for the instruments as follows: for CS-TDL $0.155 / 0.255$, AR-CWQCL 0.010/0.036, LGR-CW-QCL 0.046/0.065 and AR-PQCL $0.031 / 0.068 \mathrm{nmol} \mathrm{m}^{-2} \mathrm{~s}^{-1}$. These error statistics indicate that (i) the major component of the flux random error source is the instrumental noise and (ii) the flux errors for CS-TDL are dominantly larger than the flux magnitude, and only in the case of AR-CW-QCL can the flux error due to instrumental noise be said to be much smaller than the typical flux value.

The following fractions of fluxes were smaller than the stochastic flux error: in the case of CS-TDL, $47 \%$; AR-CWQCL, $15 \%$; LGR-CW-QCL, $28 \%$; and AR-P-QCL, $30 \%$. We conclude that apart from AR-CW-QCL, a large fraction of the fluxes were within the error magnitude of single halfhour observations.

With the new-generation analysers based on continuouswave QCL-s, $\mathrm{N}_{2} \mathrm{O}$ fluxes can be measured with the EC at locations where the fluxes are small, well below the detection limit of older instruments (CS-TDL for instance). According to our analysis, the new instruments enable one to attain the flux precision as good as the precision of the modern chamber systems. Thus, the new instruments open up the possibility of studying $\mathrm{N}_{2} \mathrm{O}$ exchange in new ecosystems, broadening scientific perspectives. 
Acknowledgements. This work was supported by the Academy of Finland (project nos. 118780 and 127456). ICOS (271878), ICOSFinland (281255) and ICOS-ERIC (281250), DEFROST Nordic Centre of Excellence and InGOS EU are gratefully acknowledged for funding this work. This work was also supported by institutional research funding (IUT20-11) of the Estonian Ministry of Education and Research. The UEF part of the research work was supported by the funding from the UEF infrastructure funding, Academy of Finland FidiPro programme (PIs - Profs Pertti Martikainen and Seppo Kellomäki) and the Ministry of Agriculture and Forestry, Finland.

Edited by: A. Neftel

\section{References}

Aubinet, M., Grelle, A., Ibrom, A., Rannik, Ü., Moncrieff, J., Foken, T., Kowalski, A.S., Martin, P.H., Berbigier, P., Bernhofer, Ch., Clement, R., Elbers, J., Granier, A., Grünwald, T., Morgenstern K., Pilegaard K., Rebmann C., Snijders W., Valentini R. and Vesala, T.: Estimates of the annual net carbon and water exchange of European forests: the EUROFLUX methodology, Advances Ecol, Res., 30, 113-175, 2000.

Christensen, S., Ambus, P., Arah, J. R., Clayton, H., Galle, B., Griffith, D. W. T., Hargreaves, K. J., Klemedtsson, L., Lind, A. M., Maag, M., Scott, A., Skiba, U., Smith, K. A., Welling, M., and Wienhold, F. G.: Nitrous oxide emissions from an agricultural field: comparison between measurements by flux chamber and micrometeorological techniques, Atmos. Environ., 30, 4183-4190, 1996.

Eugster, W., Zeyer, K., Zeeman, M., Michna, P., Zingg, A., Buchmann, N., and Emmenegger, L.: Methodical study of nitrous oxide eddy covariance measurements using quantum cascade laser spectrometery over a Swiss forest, Biogeosciences, 4, 927-939, doi:10.5194/bg-4-927-2007, 2007.

Famulari, D., Nemitz, E., Di Marco, C., Phillips, G.J., Thomas, R., House, E. and Fowler, D.: Eddy-Covariance measurements of nitrous oxide fluxes above a city, Agric. For. Meteorol. 150, 786793, 2010.

FAO, World reference base for soil resources 2006, World soil resources reports 103, Rome, Italy, 2006.

Finkelstein, P. L. and Sims, P. F.: Sampling error in eddy correlation flux measurements, J. Geophys. Res., 106, 3503-3509, 2001.

Finnigan, J. J., Clement, R., Malhi, Y., Leuning, R., and Cleugh, H. A.: A re-evaluation of longterm flux measurement techniques Part I: Averaging and coordinate rotation, Bound.-Layer Meteorol., 107, 1-48, 2003.

Flechard, C., Neftel, A., Jocher, M., and Amman, C.: Bi-directional soil-atmosphere $\mathrm{N} 2 \mathrm{O}$ exchange over two mown grassland systems with contrasting management practices, Glob. Change Biol., 11, 2114-2127, 2005.

Foken, T., Leuning, R., Oncley, S. R., Mauder, M., and Aubinet, M.: Corrections and Data Quality Control, in Eddy Covariance. A Practical Guide to Measurement and Data Analysis, Springer Science+Business Media B.V., 85-131, 2012.
Foken, T. and Wichura, B.: Tools for quality assessment of surfacebased flux measurements, Agr. Forest Meteorol., 78, 83-105, 1996.

Horst, T. W.: A simple formula for attenuation of eddy fluxes measured with first-order-response scalar sensors, Bound.-Layer Meteorol., 82, 219-233, 1997.

Huang, H., Wang, J., Hui, D., Miller, D. R., Bhattarai, S., Dennis, S., Smart, D., Sammis, T., and Reddy, K. C.: Nitrous oxide emissions from a commercial cornfield (Zea mays) measured using the eddy-covariance technique, Atmos. Chem. Phys. Discuss., 14, 20417-20460, doi:10.5194/acpd-14-20417-2014, 2014.

Järvi, L., Nordbo, A., Rannik, Ü., Haapanala, S., Riikonen, A., Mammarella, I., Pihlatie, M., and Vesala, T.: Urban nitrous oxide fluxes measured using the eddy-covariance technique in Helsinki, Finland. Boreal Env. Res., 19, 108-121, 2014.

Kaimal, J. C. and Finnigan, J. J.: Atmospheric Boundary Layer Flows. Their Structure and Measurement, Oxford University Press, New York, 1994.

Kaimal, J. C., Wyngaard, J. C., Izumi, Y., and Cotè, O. R.: Spectral characteristics of surface layer turbulence, Q. J. Roy. Meteor. Soc., 98, 563-589, 1972.

Korhonen, J. F. J., Pihlatie, M., Pumpanen, J., Aaltonen, H., Hari, P., Levula, J., Kieloaho, A.-J., Nikinmaa, E., Vesala, T., and Ilvesniemi, H.: Nitrogen balance of a boreal Scots pine forest, Biogeosciences, 10, 1083-1095, doi:10.5194/bg-10-1083-2013, 2013.

Kroon, P. S., Hensen, A., Jonker, H. J. J., Zahniser, M. S., van 't Veen, W. H., and Vermeulen, A. T.: Suitability of quantum cascade laser spectroscopy for $\mathrm{CH}_{4}$ and $\mathrm{N}_{2} \mathrm{O}$ eddy covariance flux measurements, Biogeosciences, 4, 715-728, doi:10.5194/bg-4715-2007, 2007.

Kroon, P. S., Hensen, A., Jonker, H. J. J., Ouwersloot, H. G., Vermeulen, A. T., and Bosveld, F. C.: Uncertainties in eddy covariance flux measurements assessed from $\mathrm{CH}_{4}$ and $\mathrm{N}_{2} \mathrm{O}$ observations, Agr. Forest Meteorol., 150, 806-816, 2010a.

Kroon, P. S., Schrier-Uijl, A. P., Hensen, A. , Veenendaal, E. M., and Jonker, H. J. J.: Annual balances of $\mathrm{CH}_{4}$ and $\mathrm{N}_{2} \mathrm{O}$ from a managed fen meadow using eddy covariance flux measurements, Europ. J. Soil Sci., 61, 773-784, 2010 b.

Launiainen, S., Vesala, T., Mölder, M., Mammarella, I., Smolander, S., Rannik, Ü., Kolari, P., Hari, P., Lindroth, A., and Katul, G.G.: Vertical variability and effect of stability on turbulence characteristics down to the floor of a pine forest, Tellus B, 59, 919-936, 2007.

Laville, P., Henault, C., Renault, P., Cellier, P., Oriol, A., Devis, X., Flura, D., and Germon, J. C.: Field comparison of nitrous oxide emission measurements using micrometeorological and chamber methods, Agronomie, 17, 375-388, 1997.

Lee, B. H., Wood, E. C., Zahniser, M. S., McManus, J. B., Nelson, D. D., Herndon, S. C., Santoni, G. W., Wofsy, S. C., and Munger, J. W.: Simultaneous measurements of atmospheric HONO and $\mathrm{NO}_{2}$ via absorption spectroscopy using tunable mid-infrared continuous-wave quantum cascade lasers, Appl. Phys. B, 102, 417-423, 2011.

Lenschow, D. H. and Kristensen, L.: Uncorrelated noise in turbulence measurements, J. Atm. Oceanic Technol., 2, 68-81, 1985.

Lenschow, D. H., Mann, J., and Kristensen, L.: How long is long enough when measuring fluxes and other turbulence statistics?, J. Atm. Oceanic Technol., 18, 661-673, 1994. 
Lenschow, D., Wulfmeyer, V., and Senff, C.: Measuring secondthrough fourth-order moments in noisy data, J. Atmos. Ocean. Technol., 17, 1330-1347, 2000. Mammarella, I., Launiainen, S., Gronholm, T., Keronen, P., Pumpanen, J., Rannik, Ü., and Vesala, T.: Relative humidity effect on the high frequency attenuation of water vapour flux measured by a closed-path eddy covariance system, J. Atmos. Ocean. Tech., 26, 1856-1866, 2009.

Mammarella, I., Werle, P., Pihlatie, M., Eugster, W., Haapanala, S., Kiese, R., Markkanen, T., Rannik, Ü., and Vesala, T.: A case study of eddy covariance flux of $\mathrm{N}_{2} \mathrm{O}$ measured within forest ecosystems: quality control and flux error analysis, Biogeosciences, 7, 427-440, doi:10.5194/bg-7-427-2010, 2010.

Massman, W.: A simple method for estimating frequency response corrections for eddy covariance systems, Agr. Forest Meteorol., 104, 185-198, 2000

Mauder, M., Cuntz, M., Druee, C., Graf, A., Rebmann, C., Schmid, H. P., Schmidt, M., and Steinbrecher, R.: A strategy for quality and uncertainty assessment of long-term eddy covariance measurements, Agric. For. Meteorol., 169, 122-135, 2013.

McManus, J. B., Nelson, D. D., Shorter, J. H., Jiménez, R., Herndon, S., Saleska, S., and Zahniser, M. S.: A high precision pulsed QCL spectrometer for measurements of stable isotopes of carbon dioxide, J. Modern Optics, 52, 2309-2321, 2005.

Moncrieff, J. B., Massheder, J. M., de Bruin, H., Elbers, J., Friborg, T., Heusinkveld, B., Kabat, P., Scott, S., Soegaard, H., and Verhoef, A., : A system to measure surface fluxes of momentum, sensible heat, water vapour and carbon dioxide, J. Hydrol., 188/189, 589-611, 1997.

Moore, C. J.: Frequency response corrections for eddy correlation systems, Boundary-Layer Meteorol., 37, 17-35, 1986.

Neftel, A., Flechard, C., Ammann, C., Conen, F., Emmenegger, L. and Zeyer, K.: Experimental assessment of $\mathrm{N}_{2} \mathrm{O}$ background fluxes in grassland systems, Tellus B, 59, 470-482, 2007.

Neftel, A., Ammann, C., Fischer, C., Spirig, C., Conen, F., Emmenegger, L., Tuzson, B., and Wahlen, S.: $\mathrm{N}_{2} \mathrm{O}$ exchange over managed grassland: application of a quantum cascade laser spectrometer for micrometeorological flux measurements, Agr. Forest Meteorol., 150, 775-785, 2010.

Nelson, D. D., Shorter, J. H., McManus, J. B., and Zahniser, M. S.: Sub-part-per-billion detection of nitric oxide in air using a thermoelectrically cooled mid-infrared quantum cascade laser spectrometer, Appl. Phys. B, 75, 343-350, 2002.

Nicolini, G., Castaldi, S., Fratini, G., and Valentini, R.: A literature overview of micrometeorological $\mathrm{CH}_{4}$ and $\mathrm{N}_{2} \mathrm{O}$ flux measurements in terrestrial ecosystems, Atmos. Environ., 81, 311-319, 2013.

Parkin, T. B., Venterea, R. T., and Hargreaves, S. K.: Calculating the Detection Limits of Chamber-based Soil Greenhouse Gas Flux Measurements, J. Environ. Qual., 41, 705-715, 2012.

Peltola, O., Hensen, A., Helfter, C., Belelli Marchesini, L., Bosveld, F. C., van den Bulk, W. C. M., Elbers, J. A., Haapanala, S., Holst, J., Laurila, T., Lindroth, A., Nemitz, E., Röckmann, T., Vermeulen, A. T., and Mammarella, I.: Evaluating the performance of commonly used gas analysers for methane eddy covariance flux measurements: the InGOS inter-comparison field experiment, Biogeosciences, 11, 3163-3186, doi:10.5194/bg-113163-2014, 2014.
Pihlatie, M., Rinne, J., Ambus, P., Pilegaard, K., Dorsey, J. R., Rannik, Ü., Markkanen, T., Launiainen, S., and Vesala, T.: Nitrous oxide emissions from a beech forest floor measured by eddy covariance and soil enclosure techniques, Biogeosciences, 2, 377 387, doi:10.5194/bg-2-377-2005, 2005.

Pihlatie, M., Kiese, R., Brüggemann, N., Butterbach-Bahl, K., Kieloaho, A.-J., Laurila, T., Lohila, A., Mammarella, I., Minkkinen, K., Penttilä, T., Schönborn, J., and Vesala, T.: Greenhouse gas fluxes in a drained peatland forest, Biogeosciences, 7, 17151727, doi:10.5194/bg-7-1715-2010, 2010.

Pirinen, P., Simola, H., Aalto, J., Kaukoranta, J., Karlsson, P., and Ruuhela, R.: Tilastoja Suomen ilmastosta 1981-2010, Finnish Meteorological Institute, Helsinki, 2012.

Provencal, R., Gupta, M., Owano, T. G., Baer, D. S., Ricci, K. N., O'Keefe, A., and Podolske, J. R.: Cavity-enhanced quantumcascade laser-based instrument for carbon monoxide measurements, Appl. Optics, 44, 6712-6717, 2005.

Rannik, Ü., and Vesala, T.: Autoregressive filtering versus linear detrending in estimation of fluxes by the eddy covariance method, Bound.-Layer Meteorol., 91, 259-280, 1999.

Rannik, Ü., Kolari, P., Vesala, T., and Hari, P.: Uncertainties in measurement and modelling of net ecosystem exchange of a forest ecosystem at different time scales, Agric. Forest. Meteorol., 138, 244-257, 2006.

Rannik, Ü., Mammarella, I., Aalto, P., Keronen, P., Vesala, T., and Kulmala, M.: Long-term particle flux observations Part I: Uncertainties and time-average statistics, Atmos. Environ., 43, 34313439, 2009.

Scanlon, T. M. and Kiely, G.: Ecosystem-scale measurements of nitrous oxide fluxes for an intensely grazed, fertilized grassland, Geophys. Res. Letter, 30, 1852, doi:10.1029/2003GL017454, 2003.

Schotanus, P., Nieuwstadt, F. T. M., and Debruin, H. A. R.: Temperature-measurement with a sonic anemometer and its application to heat and moisture fluxes, Bound.-Layer Meteorol. 26, 81-93, 1983.

Smith, K. A., Clayton, H., Arah, J. R. M., Christensen, S., Ambus, P., Fowler, D., Hargreaves, K. J., Skiba, U., Harris, G. W., Wienhold, F. G., Klemedtsson, L., and Galle, B.: Micrometeorological and chamber methods for measurement of nitrous oxide fluxes between soils and the atmosphere: Overview and conclusions, J. Geophys. Res., 99, 16541-16548, 1994.

Venterea, R. T., Spokas, K. A., and Baker, J. M.: Accuracy and Precision Analysis of Chamber-Based Nitrous Oxide Gas Flux Estimates, Soil Sci. Soc. Am. J., 73, 1087-1093, 2009.

Vickers, D. and Mahrt, L.: Quality control and flux sampling problems for tower and aircraft data, J. Atmos. Ocean. Tech., 14, 512 526, 1997.

Wang, K, Zheng, X., Pihlatie, M., Vesala, T., Liu, C., Haapanala, S., Mammarella, I., Rannik, Ü., and Liu, H.: Comparison between static chamber and tunable diode laser-based eddy covariance techniques for measuring nitrous oxide fluxes from a cotton field, Agric. Forest Meteorol., 171/172, 9-19, 2013.

Werle, P., Muecke, R., and Slemr, F.: The limits of signal averaging in atmospheric trace gas monitoring by tunable diode-laser absorption spectroscopy, Appl. Phys. B 57, 131-139, 1993. 
Wienhold, F. G., Frahm, H., and Harris, G. W.: Measurements of $\mathrm{N}_{2} \mathrm{O}$ fluxes from fertilized grassland using a fast response tunable diode laser spectrometer, J. Geophys. Res., 99, 1655716567, 1994.
Zahniser, M. S., Nelson, D. D., McManus, J. B., Hern-don, S. C., Wood, E. C., Shorter, J. H., Lee, B. H., Santoni, G. W., Jimenez, R., Daube, B. C., Park, S., Kort, E. A., and Wofsy, S. C.: Infrared QC laser applications to field measurements of atmospheric trace gas sources and sinks in environmental research: enhanced capabilities using continuous wave QCLs, Proc. SPIE, 7222, doi:10.1117/12.815172, 2009. 